\title{
Development, Validation, and Implementation of a Mainstreaming Process to Transition Students from Self-Contained Special Education into General Education Placements
}

\author{
Michael Ryan Hunsaker, Ph.D. ${ }^{1}$ \\ ${ }^{1}$ Department of Special Education, University of Utah
}

June 14, 2018

\begin{abstract}
We developed a set of computational tools specifically to guide qualified special education students back into general education. These tools include a decision tree to identify candidate students and elucidate successful placement in general education. Candidate students enter a process involving selection of general education classroom, data collection, and finally how to make the final transition out of special education self-contained placements. In the 2015-2016, we undertook a limited implementation of these transenvironmental programming tools and facilitated the transition of 10 of 20 identified candidate students from self-contained academic special education classrooms into general education placements. In the 2016-2017 school year, we extended this process to include 4 schools. 16 of 53 identified candidate students from self-contained academic special education classrooms were able to transition into general education placements. In an extension of the model district-wide, 9 of 26 identified students from behavior/SEL unit classrooms, and 9 of 9 identified students from Life Skills/SID unit classrooms were successfully transitioned into a general education with part-time special
\end{abstract}


education placement. A high percentage of the remaining candidates received $>50 \%$ of their day in general education classrooms and/or were placed in less restrictive self-contained classrooms. Overall, 54\% of identified candidate students were able to access a less restrictive environment as defined by IDEIA. Further computational analyses using regression tree, unbiased hierarchal clustering, and support vector machine methods are presented to demonstrate the robustness of these methods by recapitulating the results using solely data from special education evaluations.

\section{Introduction}

It is critical that evidence based transenvironmental programming methods be developed to facilitate the transition of students from self-contained special education classrooms into less restrictive environments present in the cascading services model of special education services. The cascading services model works thus: The most restrictive educational environments are homebound or hospital-based education, followed by inpatient residential schools, then specialized schools, followed by self-contained specialized classrooms, self-contained resource, general education with parttime special education/Resource services, general education with itinerant or consultation services, and with general education without special education services being the least restrictive classroom environment.

Within the United States, the relevant education law is the 2004 re-authorization of the Individuals with Disabilities Education Improvement Act (IDEIA; 20 USC $\$ 1400$ et seq Part D, Subpart 3, Sec 682). In part, IDEIA states (emphasis added):

(c) Findings. -Congress finds the following:

(1) Disability is a natural part of the human experience and in no way diminishes the right of individuals to participate in or contribute to society. Improving educational results for children with disabilities is an essential element of our national policy of ensuring equality of opportunity, full participation, independent living, and economic self-sufficiency for individuals with disabilities.

(2) Before the date of enactment of the Education for All 
Handicapped Children Act of 1975 (Public Law 94-142), the educational needs of millions of children with disabilities were not being fully met because-

(A) the children did not receive appropriate educational services;

(B) the children were excluded entirely from the public school system and from being educated with their peers;

(C) undiagnosed disabilities prevented the children from having a successful educational experience; or

(D) a lack of adequate resources within the public school system forced families to find services outside the public school system.

(3) Since the enactment and implementation of the Education for All Handicapped Children Act of 1975, this title has been successful in ensuring children with disabilities and the families of such children access to a free appropriate public education and in improving educational results for children with disabilities.

(4) However, the implementation of this title has been impeded by low expectations, and an insufficient focus on applying replicable research on proven methods of teaching and learning for children with disabilities.

(5) Almost 30 years of research and experience has demonstrated that the education of children with disabilities can be made more effective by-

(A) having high expectations for such children and ensuring their access to the general education curriculum in the regular classroom, to the maximum extent possible, in order to-

(i) meet developmental goals and, to the maximum extent possible, the challenging expectations that have been established for all children; and

(ii) be prepared to lead productive and independent adult lives, to the maximum extent possible;

Special education to general education setting transition pipelines are critical because it is far too often the case that students, once placed 
in special education, remain in their initial special education placements long after they no longer require those highly specialized and individualized special education services to achieve academic progress (AndersonInman, 1987; Conway \& Gow, 1988; Fuchs, Fuchs, \& Fernstrom, 1992; Johnson, 2005; Klotz \& Nealis, 2005). Difficulties in moving students back into the general education curriculum has led to suggestions that the cascading or tiered system of special education should be eliminated and replaced with scaffolds in the general education classroom to specifically support students identified with disabilities that impact their educational performance ( $c f$., conservationist vs. abolitionist argument in 1980s and 1990s; Anderson-Inman, 1987; Conway and Gow, 1988; Fuchs, Fernstrom, Scott, Fuchs, and Vandermeer, 1994b; Zigmond and Baker, 1995).

Lack of mobility toward less restrictive placements within the cascading model of special education is especially problematical for students that were initially placed in special education for behavioral, rather than academic, interventions at a very young age (e.g., Pre-Kindergarten students with autism placed in self-contained classrooms for maladaptive behaviors). The lack of a clear transition process to exit students from full time special education/special-class settings can be detrimental to educational outcomes (Savich, 2008). This is due to the fact that students in special education miss out on access to instructional materials used in the general education classroom and core instruction from highly-qualified grade level teachers (Brownell, Sindelar, Kiely, \& Danielson, 2010; Fuchs et al., 1992; Gersten \& Dimino, 2006; Zigmond \& Baker, 1995).

It has been suggested that special class placements are at best a separate but unequal entity in comparison with mainstream general education classrooms (Bedinim, 1990; Skiba et al., 2008; but $c f .$, counterexamples in Kauffman, Bantz, and McCullough, 2002; McLeskey, Landers, Williamson, and Hoppey, 2012). These arguments have led to discussions regarding IDEIA and the (un)intentional segregation of disabled and non-disabled students within the US public school system (Ferri \& Connor, 2005; Marchese, 2000; McCarthy, Wiener, \& Soodak, 2012; Nolan, 2004). This opinion was also alluded to in recent US Supreme Court opinions (Endrew F. v. Douglas County School Dist. RE-1, 580 U.S. _--, 2017). What this means is that, at least in the academic literature, the impetus to design methods to integrate disabled students into the general education classroom was greater during the 1980s in the early days after the authorization of IDEA than since the 2004 reauthorization of IDEIA ( $c f$., 
Peabody Re-Integration Project; Daniel, 1997; Fuchs et al., 1994b; Fuchs, Fuchs, and Fernstrom, 1993).

To address these challenges, we propose a decision making a flowchart called a Academic Mainstreaming Decision Tree to guide student profiling efforts and a specific Mainstreaming Process as specialized tools to guide transenvironmental programming with the aim of transitioning students out of self-contained special education classrooms and into the general education classroom. This flowchart was developed by taking data from the special education evaluation and performing recursive partitioning and hierarchal clustering and integrating the resulting maps into an easy to use decision tree.

The Academic Mainstreaming Decision Tree is a useful tool for selfcontained special education classroom teachers to identify candidate students that will benefit from a less restrictive classroom environment. The Mainstreaming Process formally assists teachers of identified students to transition them into those less restrictive placements. What makes these processes unique is that, unlike the earlier work on transenvironmental programming that focused primarily on transitioning students from the part time special education / Resource classroom into the general education classroom, the present pipelines were designed to transition students in special classroom placements into the general education environment, both with and without the assistance of part time special education/Resource services.

The manuscript details the development of these data focused tools and implementation of the Academic Mainstreaming Decision Tree and Mainstreaming Process to guide students out of self-contained special education and into less restrictive educational placements.

\section{Materials \& Methods}

\subsection{Development of a Mainstream Decision Tree}

The primary motivation for the development of a Academic Mainstreaming Decision Tree is the idea that access to the general education curriculum is legal right of every student, regardless classification and placement in special education (Conway \& Gow, 1988; Hocutt, 1996; Johnson, 2005). 
Although this need is universally accepted, it is often a difficult proposition to transition students out of self-contained special education classrooms and into general education classrooms full time. This can be for reasons of teacher or parent bias regarding student ability or coping skills (Marden, 2013; Praisner, 2003; Skiba et al., 2008; R. M. Smith, 2006) or the difficulties in specifically developing a process by which to undertake this type of a difficult transition (Cauley \& Jovanovich, 2006; Fuchs et al., 1994b; Kalaci, 2007).

To directly address these challenges, we developed a process whereby the basic decision making steps for student transition are undertaken in an exclusively data-driven manner. This method is loosely based on the response to intervention / multi-tier system of supports (RTI/MTSS) processes if observed from the point of view of moving down, rather than up, the tiers. This approach supplants the current system that requires teachers to use their best judgment in selecting candidate students for mainstreaming (Fuchs et al., 1994a; Fuchs et al., 1994b; Fuchs et al., 1993; Marden, 2013; Mathes, Fuchs, Roberts, \& Fuchs, 1998; Wadsworth \& Knight, 1999).

The Academic Mainstreaming Decision Tree was designed to focus only on data and thus prevent individuals from being asked or required to make judgment calls that may be informed by personal prejudices or biases regarding student potential for behavior and/or academic achievement (Raines, Dever, Kamphaus, \& Roach, 2012; Reynolds \& Shaywitz, 2009). Such data-driven decisions are important because any placements not explicitly motivated and supported by up-to-date evaluative data are legally indefensible, particularly if one applies the need for school districts to provide an appropriately ambitious educational benefit from special education, rather than the just more than de minimus standard as previously acceptable under legal statutes ( $c f$., Endrew F. v. Douglas County School Dist. RE-1, 580 U.S. _--, 2017).

To reduce the occurrence of indefensible special education decisions, the Academic Mainstreaming Decision Tree depends on data collected during initial and subsequent special education evaluations. This means that the data used for the decision making process are readily available for virtually all students and relatively standardized, at least within individual school districts or Local Education Agency (LEAs). Importantly, these data were collected by multiple members of the IEP team 
and by related service providers, so there was never a single person in charge of both collecting the data and making decisions on those results.

\subsubsection{Manual Selection of Mainstreaming LRE}

Using raw data from the student's most recent educational evaluation (raw values rather than categorical values), student allocation was determined for each student manually and annotated in a spreadsheet with the rest of the data from the above step using a combination of district rubrics for qualifying students as having Specific Learning Disabilities. These data were later used to evaluate the efficacy of the numerical analyses.

Data were collected from all students in academic self-contained classroom settings. All data were extracted from the student's most recent special education evaluation or re-evaluation. The following data were extracted: Adaptive Function (General Adaptive Composite-GAC), Full Scale IQ (FSIQ), SocioEmotional data (Anxiety, Behavioral Symptoms IndexBSI, Conduct Disorder), WJ-III NU data for academics (Basic Reading Skills, Reading Comprehension, Math Reasoning, Math Calculation, Written Language) and Curriculum Based Measures (Math and ELA/Reading). See Table 1 for specific items extracted from special education files. Table 2 details data explicitly excluded from any computational analyses $a$ priori.

These values were converted into categorical variables based on the school district rubric for classification as specific learning disability (SLD; $c f$. . Appendix B). The categorical variables are presented in Table 3.

\subsubsection{Regression Tree Development}

To determine the relative importance of different measures from the special education file, recursive partitioning was performed. These methods split the data into 2 groups initially based on the type of data that creates the most statistically reliable split among groups. This process is repeated across all resulting groups until the algorithm can find no reliable way to split the groups further. The result of this analysis is a regression tree that looks like a flowchart or decision tree. In this way, the most influential factor is on top of the resulting tree and factors are considered increas- 


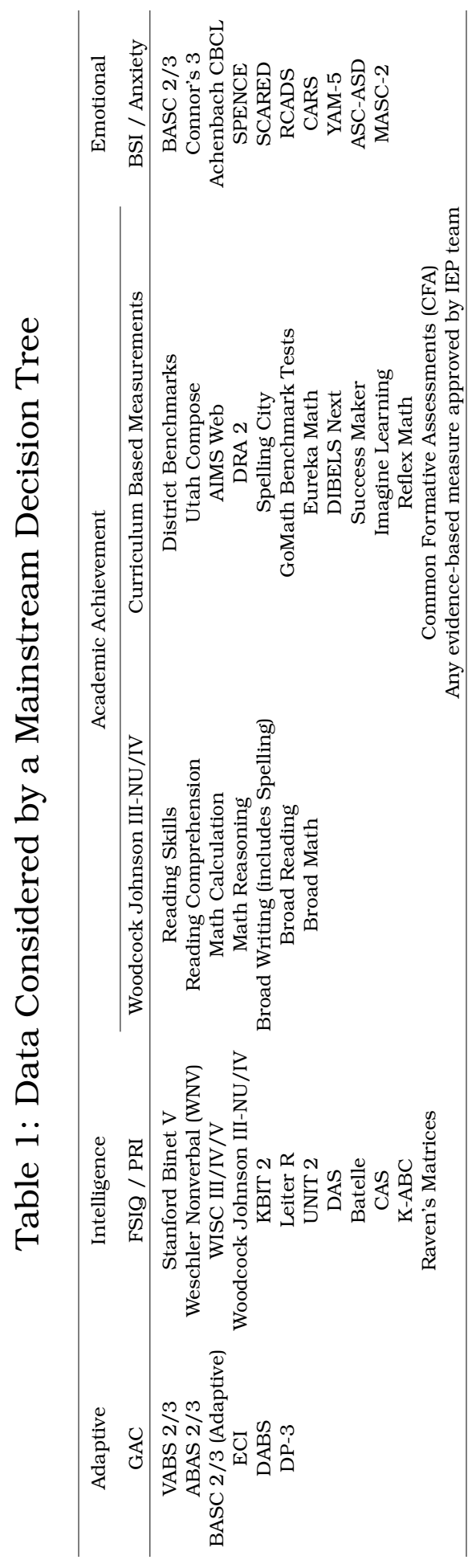


Table 2: Data Not Considered by a Mainstream Decision Tree

Desire to keep student in class as a "good example" Behavioral data from the self-contained classroom Past lack of success in mainstreaming Past lack of school skills necessary for mainstreaming Anecdotal reports of any kind not supported by data Requirement for para-educator time or increased classroom resources Student idiosyncrasies/peculiarities

Student personality

Parent concerns about academic abilities

Parent concerns about behavioral abilities

Social skills deficits

Student mobility issues

Requirement for Orientation \& Mobility Services

Use of assistive technology

Special education classification

Information regarding disability severity

Status as a non-native English speaker/Need for ELL services

Student speech issues

Selective Mutism

Aphasia

Apraxia

Stuttering

Prosody Errors

Medical/Psychiatric diagnoses

Autism

ADHD

Epilepsy

Tic Disorders

Tourette's ODD, OCD, Bipolar, BPD, etc. Anxiety/Depression status

Sensory Impairments

Visual Impairment/Blindness

Deaf-blindness

Hearing Impairment/Deafness

Sensory Processing Disorder/Need for a Sensory Diet

Current or past medications

Medication compliance or noncompliance

Hesitation of parents to pursue psychiatric help for student Quality of Relationship Teacher has with Parent

"Red Flag" or helicopter parent 


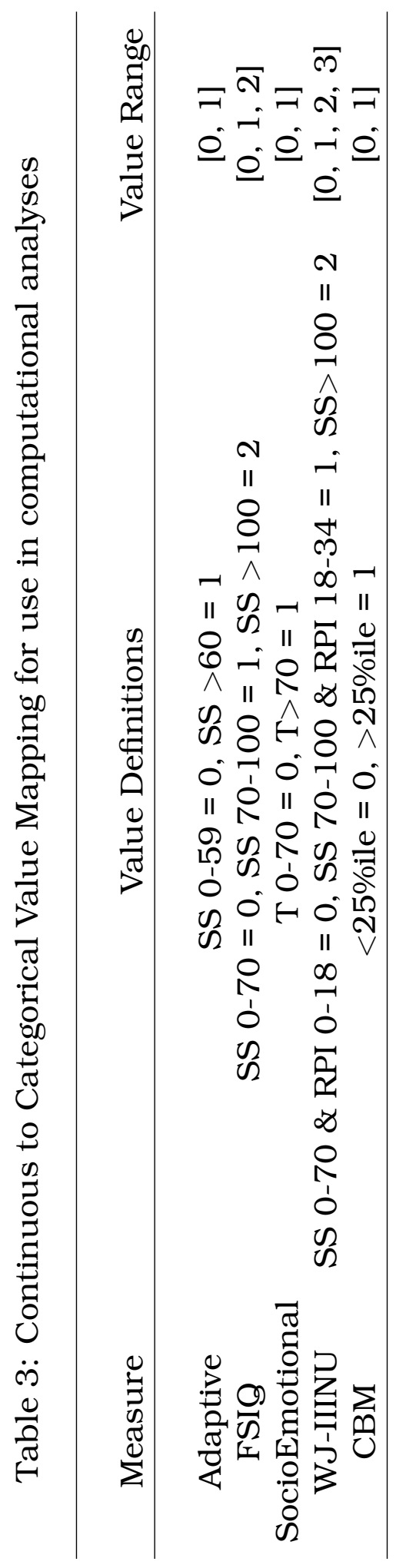

10

Accepted for Publication in "The European Journal of Education Studies" 
ingly less influential the lower they are on the tree (i.e., more influential or important factors are at the top and factors contribute less to the overall tree the further down they are located).

This analysis was performed with the rpart library in the $\mathrm{R}$ statistical computing package (R Development Core Team, 2017; Therneau, Atkinson, et al., 2017). This analysis was performed 3 times, first with the academic data included (mean scores across WJ-III NU as well as mean scores across CBM), once with academic information withheld, and once with the CBM and WJ-III NU measures separated. The second condition that left out all academic data was considered critical as often times the files for incoming students in $\mathrm{K}-2^{\text {nd }}$ grades with classifications of DD, AU, SLI, or OHI most often lack academic testing or else previous teams have deemed those results unreliable. Once the rpart code was executed, the resulting tree-based visualizations were saved to file and remained unaltered. A deliberate choice was made to not cut the trees using a prune command or post process them in any way for the sake of transparency.

The R code for the recursive partitioning was:

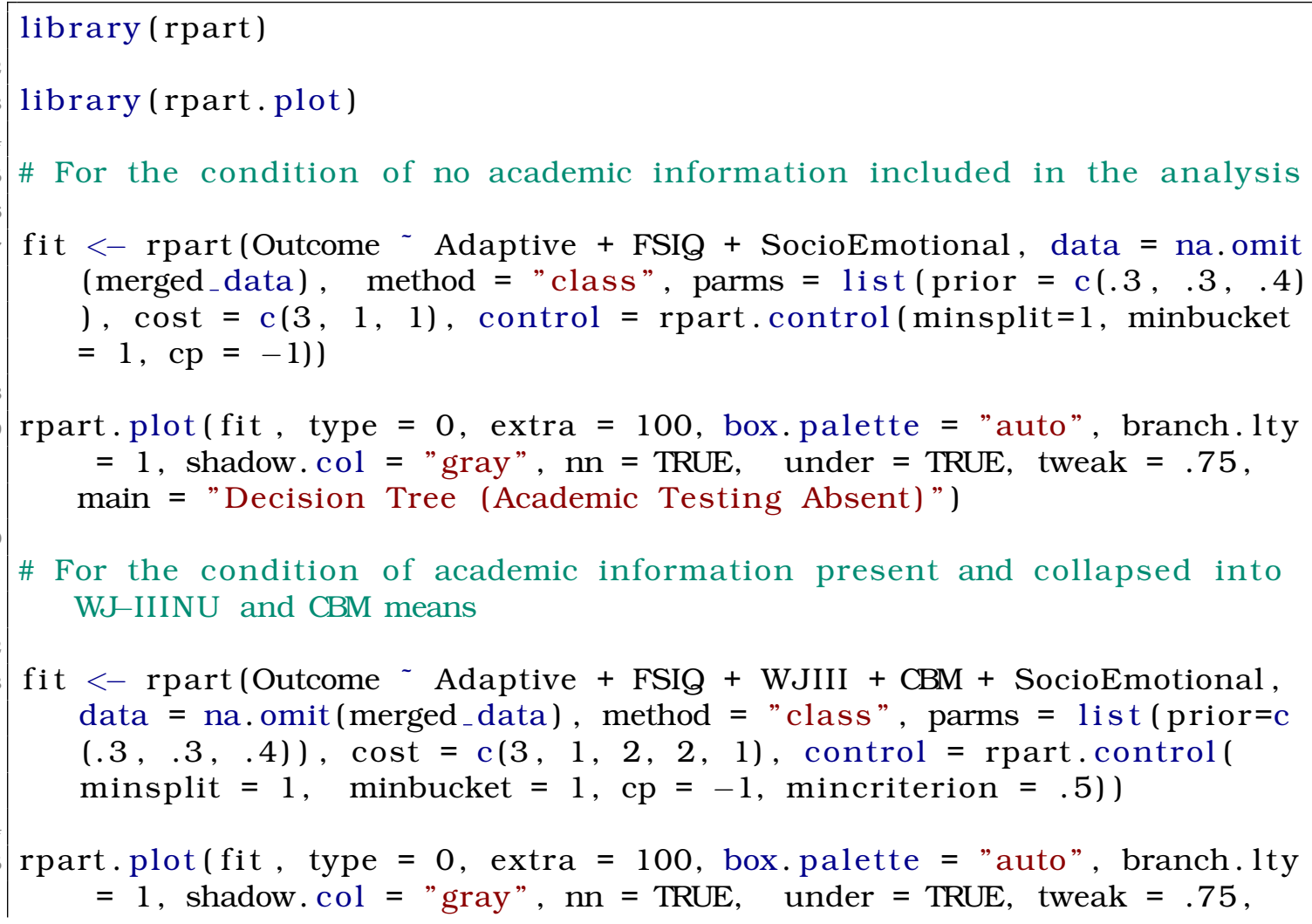




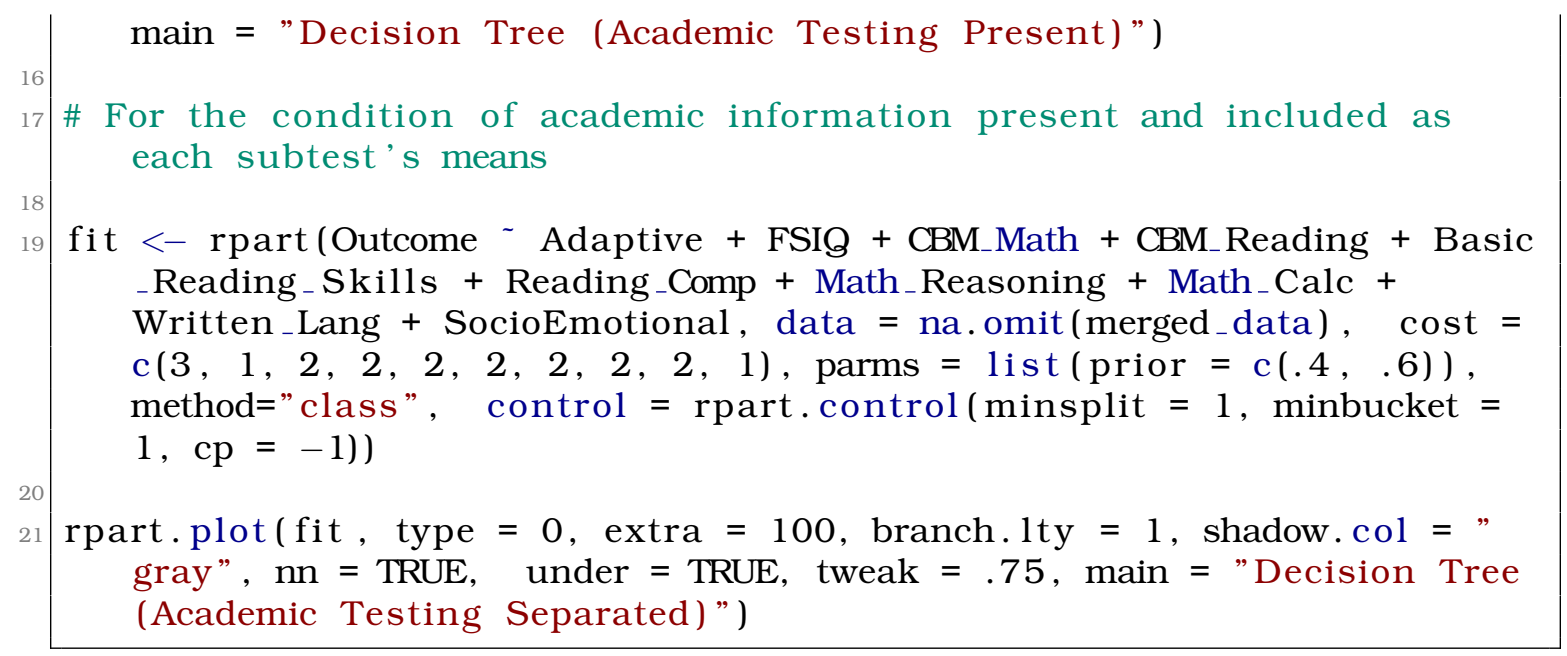

\subsubsection{Regression Tree Interpretation}

As can be seen from the partition tree in Figure 1, when academic testing is not available, the rpart algorithm used Adaptive Function as the first split point, supporting previous research that suggests academic and social success depends heavily on adaptive function. SocioEmotional data then seems to be the next most important data for determining student placement, followed by FSIQ data (Figure 1).

When academic information is included as means for ELA/Reading and Math across the WJ-III NU and CBM, CBM (indicating classroom performance) is the primary determining factor for success, followed by WJ-III NU and SocioEmotional function. FSIQ appears to only become involved when very low WJ-III NU scores are present and there are some SocioEmotional challenges reflected in high values (Figure 2). A further recursive analysis was undertaken wherein all CBM and WJ-III NU data were included as individual items and not averaged together. The resulting regression tree suggested CBM performance in math, followed by reading comprehension and math reasoning were the most critical academic factors, with Basic Reading Skills, CBM Reading, Math Calculation, and Written Language scores showing less influence (Figure 3). 


\section{Decision Tree (Academic Testing Absent)}

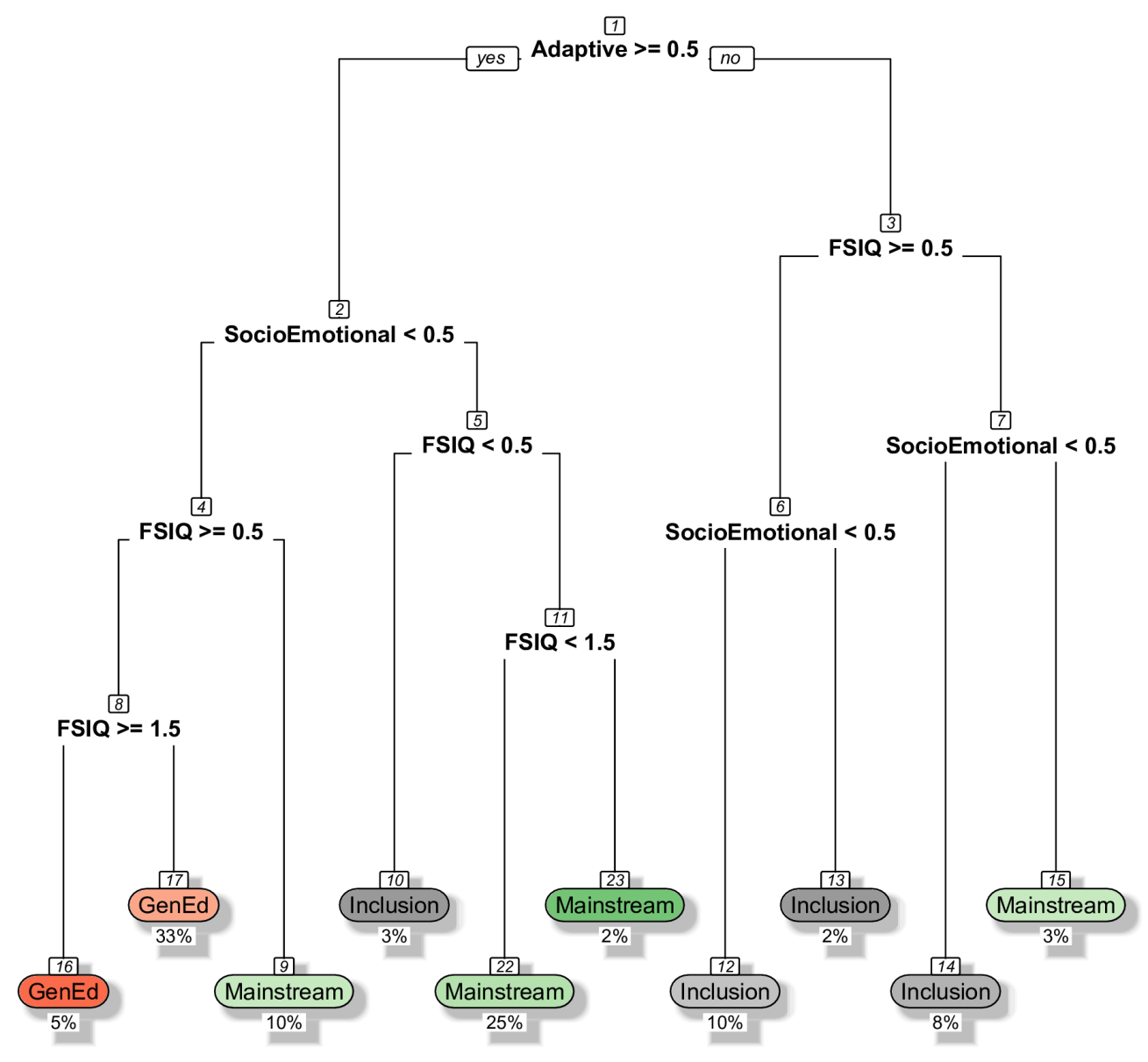

Figure 1: Results of a Regression Tree Analysis without Academic Data. The results demonstrate that adaptive function is the most influential data in student placement, followed by SocioEmotional and Full Scale IQ. Interestingly, for students with Adaptive scores $>60$, SocioEmotional data have a higher influence than IO scores. The opposite is true for low adaptive scores. 


\section{Decision Tree (Academic Testing Present)}

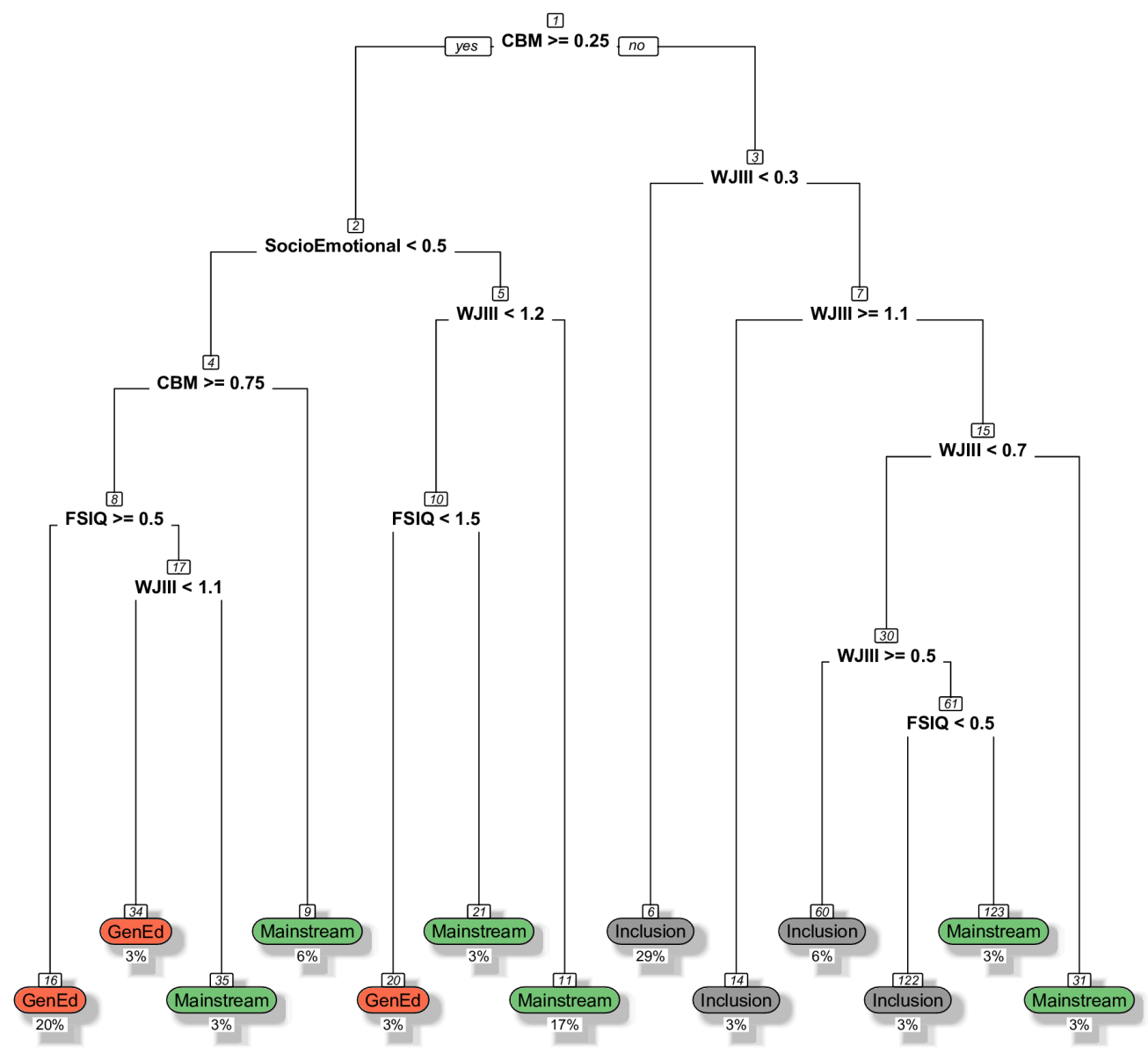

Figure 2: Results of a Regression tree analysis with academic data. When academic data are included in the regression tree, it is clear that curriculum based measures are the best predictor of student success. This is intuitive since the best measure of success is success itself, which is what CBM measure. For high CBM values, SocioEmotional function is the next important feature, followed by academics and IQ. For low CBM, it appears that the important factors are academic performance on the WJ-III NU followed by IQ measures. 
Decision Tree (Academic Testing Separated)

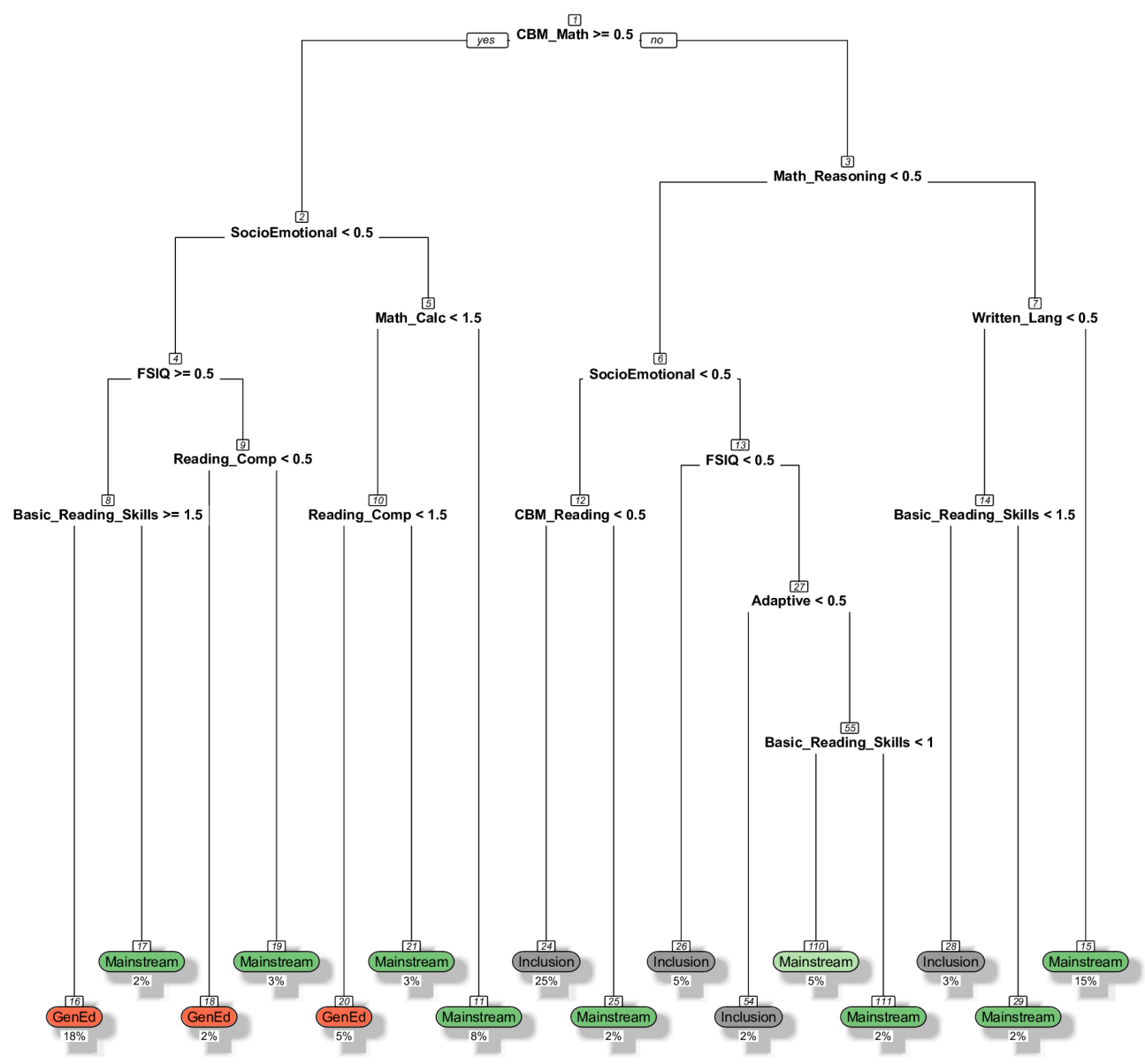

Figure 3: Results of a Regression tree analysis with academic data separated. When academic data are included in the regression tree, it is clear that curriculum based measures are the best predictor of student success. This is intuitive since the best measure of success is success itself, which is what CBM measure. CBM performance in math, followed by Reading Comprehension and Math Reasoning were the most critical academic factors, with Basic Reading Skills, CBM Reading, Math Calculation, and Written Language scores showing less influence. 


\subsection{Hierarchy of Measures Included in Mainstream Deci- sion Tree}

For ease of interpretation and allow for a computational implementation of a regression tree a decision making rubric, the results seen in Figure 1, Figure 2, and Figure 3 were synthesized into a single document. Judgments were made regarding the hierarchy of measures included in the Academic Mainstreaming Decision Tree based on clinical and school psychology research. There was a conscious effort undertaken to emphasize nonacademic factors as it was hypothesized that many students may perform poorly on academic testing due to previous lack of exposure to the curriculum or testing methods. The resulting Academic Mainstreaming Decision Tree is shown in in Figure 4 and Appendix C.

The hierarchy followed by the Academic Mainstreaming Decision Tree is Adaptive Function as the first decision point, followed by Full Scale IQ, Academic Achievement, and finally SocioEmotional Well Being. These items were placed in this order to maximize predictive validity of the process by emphasizing certain measures at earlier or later stages of decision making. The flow of decision points can be seen in Figure 4 looking from top to bottom. Judgment calls were made by extracting data from the recursive partitioning to observe relative weightings of factors. Appeal to the published literature on how each of these factors associate or correlate with student academic success was also used to sort factors (Angkustsiri et al., 2012; Bearden et al., 2004).

Important for understanding the intent of the Academic Mainstreaming Decision Tree is the operation difference between inclusion and mainstreaming used in this manuscript. The broad generally accepted approach to inclusion and mainstreaming are described below.

Inclusion is the process of giving a student in special education access to the general education classroom to comply with LRE. For students with disabilities, advantages to this process are the opportunity to form friendships with their peers from whom they would have been separated if educated in a separate classroom. It allows students with disabilities to interact with non-disabled students to the benefit of all; they will all learn how to work together, gaining invaluable skills for the future. Students taught in a classroom with inclusion will learn to be more accepting and respectful of people from different backgrounds. 


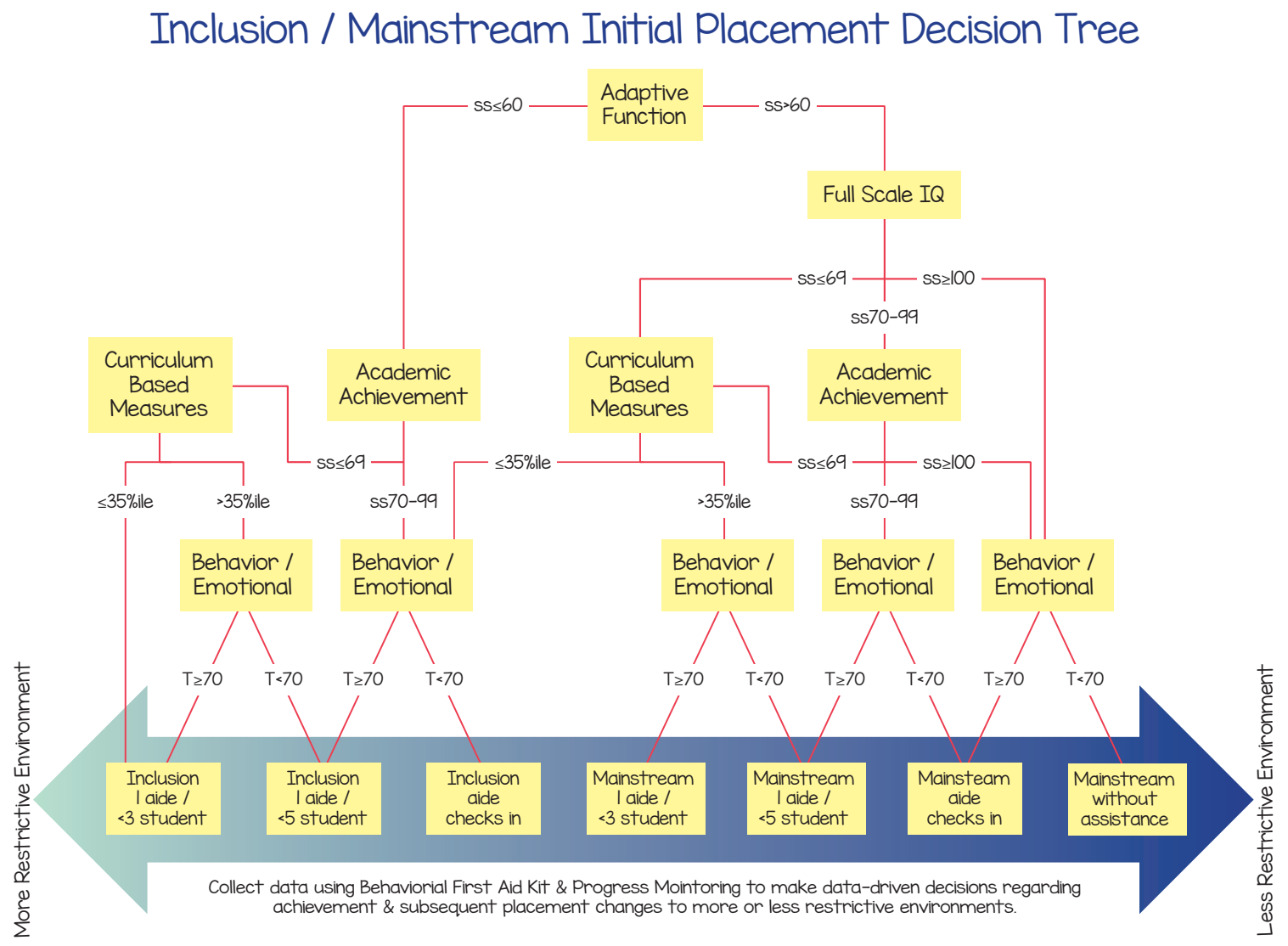

Figure 4: Academic Mainstreaming Decision Tree. The Academic Mainstreaming Decision Tree is a visual depiction of the datadriven decision making process used to identify candidates for transition from self-contained special education to general education with part time special education/Resource services placements. Data regarding Adaptive Function is the first decision point, followed by Full Scale IQ, Academic Achievement, and SocioEmotional Well Being. Along the bottom are the spectrum of restrictive environments ranging from inclusion with an aide on the left to independent mainstream access to the general education classroom on the right. 
Mainstreaming is the term used to describe integrating students with disabilities into regular learning environments. Mainstreamed students have high potential for success, but it is vital that they receive support personalized for their needs by their IEP team. It is bringing special education services to the child rather than removing the child from the regular classroom. Some benefits of mainstreaming often include higher academic success, increased self-esteem and more astute social skills.

To be more explicit, the operational definitions used by the present Academic Mainstreaming Decision Tree and Mainstreaming Process are as follows:

- Inclusion refers to social access to peers in a general education classroom. Assignments are often highly modified for inclusion (assignment modification means entirely different materials or assignments that reduce the expectations on student achievement or alteration to the required curriculum). A student can receive full day special education services in a general education classroom via push-in services and not share any academic goals, demands, or instruction with their general education peers and still be receiving "full inclusion". This is often why the term inclusion will be used to describe both a general education classroom that has disabled students attend as well as the special education classes themselves and specialized schools (i.e., "inclusive schools").

- Mainstreaming refers to academic access to the general education classroom. Assignments, tests, and curriculum have to be the same as general education peers or slightly adapted/accommodated (meaning the expectations for achievement and curriculum requirements remain the same, but the assignment can be changed by response mode or reduction of work load to facilitate student success), but cannot be modified. In this way a student mainstreaming in a general education classroom will be receiving academic instruction with their general education peers and, as a result, will be receiving fewer special education services as a result of their mainstreaming.

The reason we focus on these definitions is that the intent of the verbiage in IDEIA (2004) is that students receiving special education receive as much of their academic education in a general education classroom as is possible for the student. This is not only for the social benefits, 
but for the students to have access to the high quality instruction and high standards in the general education classroom. It is only in this way that students can show the necessary growth toward college and/or career readiness, which is the goal for special education as well as general education students.

\subsubsection{Adaptive Function}

Adaptive function was emphasized because it underlies the practical, everyday skills needed to function and meet the demands of an individual's environment, including the skills necessary to effectively and independently take care of oneself and interact with other people (Oakland \& Harrison, 2011). Intact adaptive skills are crucial to achieving success in a general education classroom environment. Adaptive Function was chosen as the first decision point because of its pivotal role in behavioral flexibility when encountering novel or difficult situations. Adaptive function is an individual's competence of social and practical daily living skills (De Bildt, Sytema, Kraijer, Sparrow, \& Minderaa, 2005; Ditterline, Banner, Oakland, \& Becton, 2008; Gresham \& Elliott, 1987). Adaptive skills are necessary for an individual to adjust their behavior to novel situations or contexts (i.e., change inappropriate behaviors to more appropriate ones given a change to the encountered situation).

Having adaptive function as the first decision point makes the Academic Mainstreaming Decision Tree rather conservative so far as taking student coping skills and adaptability into account. Low adaptive composite standard scores result in initially placing the student in more restrictive settings with increased behavioral and academic supports. Once the student responds favorably with these supports, the student progresses toward increasingly less restrictive educational settings. An important note is that if the student appears to show a relative adaptive strength in the sub-measures of adaptive function that relate to schoolwork, that relative strength may be taken into account to generate an alternative path down the Academic Mainstreaming Decision Tree. 


\subsubsection{Cognitive/Intellectual Abilities}

IQ tests measure an individual's cognitive faculties of intellect in comparison to others. The results of IQ tests are proxy to the mental agility of a person. Importantly, intelligence had not been shown to underly academic achievement, in most cases intelligence, at best only weakly correlates with achievement measures (Konold, Kush, \& Canivez, 1997; Wechsler, 2008); or, in some cases such as students with developmental disorders or autism, FSIQ values fail entirely to correlate with an individual's ability to be successful and may actually underestimate intelligence so greatly as to effect placement decisions (Biswas \& Furniss, 2016; Dennis et al., 2009; Grondhuis et al., 2018; Nader, Courchesne, Dawson, \& Soulieres, 2014; Popa et al., 2014).

Intellectual Abilities (Full Scale IQ) were given lower priority relative to adaptive function simply because a low IQ can be unduly influential if included as the first step of a decision making process. Decades of research suggest IQ measures can be poor predictors or correlates of cognitive ability and academic success in developmentally disabled populations that are well represented in special education classrooms (e.g., spina bifida, autism, and 22q11.2DS; Biswas and Furniss, 2016; Dennis et al., 2009; Nader et al., 2014; Popa et al., 2014). In fact, it has been repeatedly demonstrated that there are systematic biases in IQ tests, with many underestimating cognitive abilities more than others (examples for StanfordBinet V and WISC-III/IV systematically underestimating cognitive abilities in autism $c f$., Barbeau, Soulieres, Dawson, Zeffiro, and Mottron, 2013; Courchesne, Meilleur, Poulin-Lord, Dawson, and Soulieres, 2015; Dawson, Soulieres, Gernsbacher, and Mottron, 2007; Nader, Courchesne, Dawson, and Soulieres, 2016).

\subsubsection{Academic Achievement}

Academic Achievement was chosen to be the next decision step. We focus on the Woodcock-Johnson III Norms Updated (WJ-III NU) and WoodcockJohnson IV (WJ-IV) because these assessments were the primary tool to assess academic achievement in school districts in Utah at the time of this writing.

The WJ-III NU Tests of Achievement were widely used to assess 
students for learning disabilities and the resulting data were useful for determining if the students qualified for specialized services. The WJ-III NU Tests of Achievement uses clusters of tests that directly parallel critical learning goals outlined by IDEIA and provide procedures for determining discrepancies between student potential and achievement. Curriculum based measures were used as direct measure for classroom performance relative to peers in general education environment (Edwards \& Oakland, 2006; Taub \& McGrew, 2004; Wu, West, \& Hughes, 2008).

However, the use of appropriate curriculum based measures often gives a more complete snapshot of academic achievement by directly measuring academic skills in the classroom (Mathes et al., 1998). Specifically, with the increasing prevalence of grade-wide common formative assessments (CFA) in the general education classroom, these can be even more reliable and up-to-date indicators of success than standardized summative achievement tests students are given either annually or every third year (Dunn \& Mulvenon, 2009; Heritage, 2007; Mathes et al., 1998). As such, curriculum based measures were given priority over achievement scores from the WJ-III NU when there was a discrepancy.

\subsubsection{SocioEmotional Well Being}

Academic problems, along with problems associated with developing and maintaining positive relationships with others, are often the result of underlying behavioral and emotional challenges. These challenges, when identified and addressed sufficiently early, can be corrected before negatively affecting a child or adolescent (Raines et al., 2012; Reid, Gonzalez, Nordness, Trout, \& Epstein, 2004).

SocioEmotional Well Being is the final decision point in the Academic Mainstreaming Decision Tree. This was intended to quantify anxiety and/or emotional self regulation that deleteriously impact classroom performance. Behavioral and conduct problems that require behavioral intervention can be considered as well at this step (e.g., Behavioral Symptoms Index (BSI) on the BASC-2/3 or Conduct Problems on the Connors 3 and/or Achenbach CBCL). These data were included because behavioral and emotional functioning of children and adolescents are often effective measures for predicting student success (Wiesner \& Schanding, 2013).

The decision to place SocioEmotional Well Being as the final deci- 
sion step was deliberate. Once the other factors have been accounted for in the decision making process, this step modulates earlier decisions by placing the student in either a slightly more or less restrictive environment based upon their anxiety and/or social, emotional, behavioral profiles. In other words, SocioEmotional Well Being was used explicitly to provision increased support for the student if needed to prevent student perception of being overwhelmed by the level of challenge in the classroom. The working model used to describe the role of anxiety or behavioral disorders on student success was based on the Yerkes-Dodson inverted U Function (cf., Figure 5; Cohen, 2011; Cooray and Bakala, 2005; Yerkes and Dodson, 1908).

\subsubsection{Provisioning Academic Support}

Whether to initially place the student in a more or less restrictive environment is the result of the Academic Mainstreaming Decision Tree. As seen in Figure 4, the Academic Mainstreaming Decision Tree results in candidate placements for inclusion or mainstreaming and suggests a level of restrictive environment that will be appropriate for each student. As students exhibit increased independence, academic and behavioral supports can be gradually faded back, resulting in movement toward a less restrictive environment (i.e., toward full independence in the general education classroom).

Fading back supports is done in two phases, behavioral and academicwith behavioral scaffolds being released first. For both academics and behavior, the first step is to fade supervision based on least restrictive environment. This means reduced access to inclusion/mainstreaming paraeducators until the student achieves independence. The next step was to provide specific incentives for continued academic and behavioral successes.

If students require greater supports in order to be successful, then more supports and scaffolds can be added, moving the student into more restrictive environments that requires less student independence. To scaffold behavioral success, the first step is to provide incentives to build on achieved successes. Then, if necessary, provide behavioral support in the form of a paraprofessional. These supports can take the form of social skills, emotional, or behavioral interventions. 


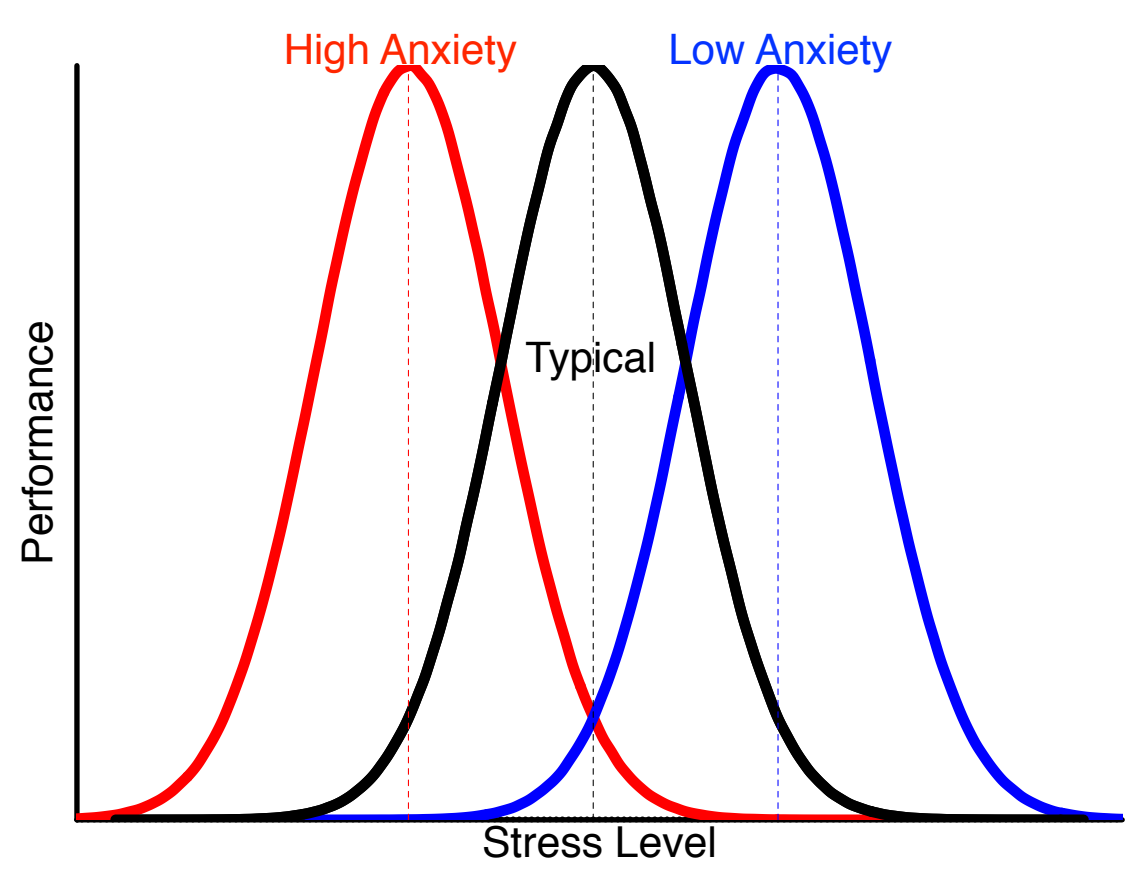

Figure 5: Yerkes-Dodson Inverted $U$ Function applied to anxiety after (Yerkes $\&$ Dodson, 1908). There was a clear relationship between stress and performance, with more stress (or challenge) being required to increase performance up to a point. After that point, there was too much stress and performance decreases. The middle curve line is a model curve for a "typical" student. The high anxiety student line (e.g., $T_{\text {anxiety }}>70$ on $B A S C$ 2) shows that student performance peaks at lower stress levels. This suggests the students need increased support to shift the curve rightward where the typical curve is located. Low anxiety student performance peaks at higher stress levels. This suggests they need to be pushed and challenged to shift the curve leftward to where the black curve was located, as they are showing poor performance at "typical" levels of perceived stress. 
To provide academic scaffolds, the first step is to provide incentives for continued academic success. If needed, assignments are adapted (assignments and grade level expectations are still never modified). Finally, pull-out or push-in academic services are provided to bridge knowledge gaps as needed.

\subsection{Behavioral Mainstreaming Decision Tree}

In parallel with profiling a student's academic needs using the Academic Mainstreaming Decision Tree, it is also necessary to quantify their behavioral needs. To accomplish this, we created a Behavioral Mainstreaming Decision Tree (Figure 5 and Appendix D). This was designed for mainstreaming decisions for students in SocioEmotional Learning/Emotional Disturbance/Behavior unit classrooms.

Similarly to how the Academic Mainstreaming Decision Tree relies on data rather than teacher or student judgment, the Behavioral Mainstreaming Decision Tree focuses on behavioral data easily collected by the classroom teacher and validated by other faculty or staff as fidelity checks. What the Behavioral Mainstreaming Decision Tree does not do, however, is rely on classroom contract or level systems for inclusion/mainstreaming determination (Iwata \& Bailey, 1974; S. W. Smith \& Farrell, 1993). This decision was made to mitigate the influence of bias on the part of classroom teachers or paraeducators when marking contracts on mainstreaming decisions (cf., Group, 1991; Ruth, 1996).

\subsubsection{Seclusionary Time Out/Time Out Booth}

The first component of the Behavioral Mainstreaming Decision Tree is whether the behavior of the student require use of seclusionary time out/Time Out Booths or Physical Restraint (also called Forced Physical Guidance or Manual Restraint in some LEA). The use of these emergency safety interventions is limited in most areas to instances where the behavior of the student is an immediate and significant danger to themselves or others. Only the cases of seclusionary time out was used a an Emergency Safety Intervention were considered for the Behavioral Mainstreaming Decision Tree. All other uses were recorded separately and staff were retrained on use of these interventions. If a student requires the use of 
these interventions, they require instruction in social skills and SocioEmotional self regulation prior to attempting any mainstreaming or social inclusion.

\subsubsection{Physical Aggression}

The second component of the Behavioral Mainstreaming Decision Tree is whether the student engages in physical aggression. Importantly, this does not include property destruction. A student destroying property and a student attacking another person are very different things and should not be confounded. Physical aggression includes punching, kicking, slapping, head-butting, using chairs, pencils, etc as weapons to hit another, spitting on, or biting another person.

Importantly for this component, I differentiate between a physical aggression even if the student was provoked by another student or teacher in the room and those when the student aggresses without clear provocation. Provocation in this sense includes peers or adults making physical contact with a student or restricting their movement. Similarly, peers or adults using "fighting words" to escalate a student or specifically trigger them is considered provocation.

\subsubsection{Inappropriate Vocalizations}

The third decision point is that of inappropriate vocalizations. If a student engages in pervasive inappropriate language or vocalizations they will be considered for a more restrictive mainstreaming placement compared to if they do not. For this decision point, inappropriate vocalizations include very specific things: they include screaming used to back off adults or teachers. They also include using specifically course and vulgar language.

For clarity, this means if a student is generally talking about Slenderman or killing or hurting someone that does not count as an inappropriate vocalization so long as it is not a credible threat. If a student uses words like damn, shit, bitch, bastard, fart, poop, etc. I do not count these, regardless the community standards. If students use words like fuck, shit, cunt, cock, anatomically accurate or crass description of sex organs, explicit or accurate descriptions of rape, torture, etc. I do consider these inappropriate vocalizations. I draw this line where I do as the latter set 
of vocalizations do not tend to go away in a new environment and with minimal instruction to the student on community standards. The former do. Basically if students are using vulgar, sexually explicit, or language not easily observable on broadcast television, the use of that language is an intentional, conscious choice and the student will require significant intervention prior to being placed in a stressful situation with other students.

\subsubsection{Provisioning Behavioral Support}

Similarly to the Academic Mainstreaming Decision Tree, the next component is to choose the level of support necessary for mainstreaming. Mainstreaming/IEP team meetings should happen biweekly to determine if a more or less restrictive environment is necessary for student success. As students exhibit increased independence, academic and behavioral supports can be gradually faded back, resulting in movement toward a less restrictive environment (i.e., toward full independence in the general education classroom).

Fading back supports is done in two phases, behavioral and academicwith behavioral scaffolds being released first. For both academics and behavior, the first step is to fade supervision based on least restrictive environment. This means carefully reducing access to inclusion/mainstreaming paraeducators as the student achieves increasing levels of self sufficiently and independence. The next step was to provide specific incentives for continued academic success and behavioral successes.

If students require greater supports in order to be successful, then more supports and scaffolds can be added, moving the student into more restrictive environments that demand a lower level of student independence. To scaffold behavioral success, the first step is to provide incentives to build on achieved successes. Then, if necessary, provide behavioral support in the form of a paraprofessional. These supports can take the form of social skills, emotional, or behavioral interventions.

To provide academic scaffolds, the first step is to provide incentives for continued academic success. If needed, assignments are adapted (assignments are still never modified). Finally, pull-out or push-in academic services are provided to bridge gaps as needed.

Critically, if the two different decision trees (academic and behav- 
ioral) result in different levels of restrictive environment, the team will meet to harmonize the differences between the results and what placement is in the best interest of the students.

\subsection{Mainstreaming Process}

Once candidate students were identified and placed in an appropriate setting for inclusion/mainstreaming using the Academic Mainstreaming Decision Tree, then a specific transenvironmental programming process needs to put into place to guide students toward success in increasingly less restrictive environments. This pipeline was designed to simultaneously build student confidence and ability by stretching and challenging them both academically and behaviorally while providing sufficient scaffolds and support to prevent student failure. To achieve effective transenvironmental programming methods, we developed a 7-step Mainstreaming Process based on previous research (Fuchs et al., 1994b; Fuchs et al., 1993; Marden, 2013; Mathes et al., 1998; Wadsworth \& Knight, 1999).

\subsubsection{Step 1 - Identify Candidate Students}

As described above, candidate students were identified with the Academic Mainstreaming Decision Tree using broad Adaptive scores (Adaptive Composite Standard Score from ABAS-II/ABAS-3 or VABS-II/VABS-3 or else adaptive T-score on BASC2/3), Full Scale IQ (or NVIQ/VIQ as appropriate), Academic Achievement (CBM/CFA or WJ-III NU/IV), and SocioEmotional Well Being. To do this, a copy of the Academic Mainstreaming Decision Tree was printed and a highlighter was used to trace down the decision points for each student individually to identify initial inclusion/mainstreaming placement options. The values at each decision point were annotated in a Mainstreaming Data Sheet (form available as Appendix E). In parallel, the student data and placement allocation was extracted from the recursive partitioning data to be compared with the Academic Mainstreaming Decision Tree.

Note, not at this point nor at any other point moving forward were special education classification, medical diagnoses, mobility problems, speech issues, or anything else included in Table 2 considered as factors affecting placement decisions. Neither did teachers consider 
past difficulties in mainstreaming except as motivation for the development of behavioral plans to scaffold student success. The final element within this step was to write a very precise description of each student in terms of temperament and relative need for structure compared to peers (both comparisons to special education and grade level general education peers).

\subsubsection{Step 2 - Identify Classroom Placements}

Once candidate students are identified, it becomes critical to identify grade level classrooms as placement options. There are two approaches to doing this: First, one can identify teachers with a known history of working with special education. Second, one can refrain from limiting candidate classrooms to any given teacher, but look at all grade level classrooms to determine best placement options on a student by student basis.

The preferred option is to evaluate all grade level classrooms as candidate placements. This prevents issues associated with the special education department overwhelming a relatively small number of teachers with extra students while not impacting other classrooms within the school (Avramidis, Bayliss, \& Burden, 2000; Barnes \& Gaines, 2015; Mukherjee, Lightfoot, \& Sloper, 2000). Additionally, all efforts were made to spread students in the same grade across classrooms rather than grouping them together. This was done for two reasons. The first being to prevent overloading a general education classroom with multiple potentially burdensome students. It was emphasized that best practices were to keep the natural ratios of general education to special education students intact; meaning 10-15\% of any class could be special education students, but no more. The second reason was to foster independence by challenging the special education students in a new environment without being able to use their peers as a crutch for either bad behavior or seeking help instead of persevering during academic tasks. Any teacherstudent personality considerations based on the profile completed in Step 1 should be addressed with the building administrator prior to moving forward with any placements. 


\subsubsection{Step 3 - Classroom Ecological Inventory}

This step involves harmonizing the special education and general education environments to maximize the potential for student success. It was based strongly on the evidence based transenvironmental programming methods employed by the Peabody Reintegration Project and refined by Fuchs and colleagues (Fuchs et al., 1994b; Fuchs et al., 1993; Marden, 2013; Mathes et al., 1998; Wadsworth \& Knight, 1999).

The individual steps/components to this Classroom Ecological Inventory process are as follows:

1. Special education teacher (or district facilitator/coordinator) observes candidate general education classrooms to identify any issues that will limit success as well as identify classroom factors that will increase probability of student success.

2. The special education and general education teachers independently complete a shared ecological inventory for their classrooms that can be used to identify any discrepancies in classroom environment that may impact student success (modified after previous examples in the literature; Fuchs et al., 1994b; Marden, 2013). In other words, the special education and general education teachers describe their classroom environment, expectations, management styles, etc. The form developed for the Mainstreaming Process is available as Appendix $\mathrm{F}$.

3. Any discrepancies among the different teachers' responses to the inventory were identified and discussed to identify and anticipate potential difficulties for the student moving forward.

4. The general education and special education teachers meet and discuss plans/solutions to potential difficulties for the student based on the data from the ecological survey. The most common issues observed were increased rigor of curriculum in general education compared to special education, insufficient student independence in special education, and different curricula between special education and general education. The most commonly proposed solutions were planned accommodation of assignments (to be faded over time), increasing academic rigor in the special education classroom 
as the student is transitioning to the general education context, and special education classrooms increasing homework load prior to the transitions so the student develops the academic skills required by homework.

5. The special education and general education teachers specifically plan classroom accommodations for moving forward. This step involves a number of informal meetings and an in depth conversation as to precise expectations regarding student performance in the general education classroom. The district facilitator often had to intervene at this stage to verify that expectations for the special education student were both realistic but also aligned to expectations for the other students in the classroom.

Critically, it was emphasized that there could be zero assignment modification during any step of the mainstreaming process. Assignments could be adapted so the student could access the curriculum (e.g., change response mode or reduce total work load), but no expectations for curriculum or content mastery could be reduced. This emphasis was placed because it has been shown that excessively modifying assignments and reducing expectations for content mastery impede long term transition out of special education, whereas appropriate accommodations that maintain high content mastery expectations increase the probability of future success and a reduction in the need for future accommodations (Fisher, Frey, \& Thousand, 2003; Fuchs, Mock, Morgan, \& Young, 2003; Hollenbeck, Tindal, \& Almond, 1998).

\subsubsection{Step 4 - Initiate Student Placement in General Education Class- room}

The Academic Mainstreaming Decision Tree can be used to identify the specific needs of the student for support levels. It is only at this time point in the process that the need for para-educator allocation and student specific behavior plans are explicitly discussed. The student is placed in the general education classroom for $\tilde{5} 0 \%$ time to begin (unless the IEP team decision was to start with a greater percentage of time).

Upon beginning to attend the mainstream classroom, the special education teacher begins data collection on student independence 
using a Mainstreaming Data Sheet (Appendix D). Data collection on independence, levels of accommodation necessary for student success, and classroom behavior were also collected by a district facilitator/coordinator. Behavioral data sheets used during this implementation are available as editable digital files by request or available for download at https:// github.com/mrhunsaker/BehavioralFirstAid/ under a GNU General Public License v3.0.

\subsubsection{Step 5 - Transition from Part-Time to Full-Time General Edu- cation}

Student time is increased in the general education class until they independently participate $90-100 \%$ of the time in the general education classroom and/or Resource classroom prior to moving toward a re-evaluation / placement change. Any increases of student time in general education classroom or movement in the direction of transitioning toward change of placement are based on the following factors: 1) Independence as quantified by a Mainstreaming Data Sheet, 2) Classroom observations, 3) Work completion, and 4) Academic progress, primarily referring to how much accommodation the student needs (i.e., whether or not the student completes coursework with the same assignments as peers receiving only part time special education/resource services). This final criteria is important because the majority of students transitioning out of self-contained classrooms will need part time special education/resource services to achieve success.

\subsubsection{Step 6 - Formal Transition from Special Education to General Education}

The IEP team performs an official data review to determine how to proceed with a change of placement. Additional academic testing can be administered (e.g.,WJ-III NU/IV) as part of a re-evaluation to elucidate present levels of academic functioning and performance if CBM benchmarks and CFA performance were insufficient. These results guide IEP goal development and to elucidate appropriate levels of part time special education/Resource services.

During this transition, the IEP team develops all necessary be- 
havior plans, contracts, trackers, etc. Any plans or contracts must be designed to fit seamlessly into the school PBIS framework or other schoolwide discipline system.

\subsubsection{Step 7 - Transition from Unit School to Neighborhood School}

At the end of the year, there should be a transition meeting between the IEP team and the student's neighborhood school to discuss necessary accommodations, successes, challenges, etc. The following issues need to be discussed: 1) Transition plans: decisions need to be made whether the student returns to their neighborhood school or stay at the school wherein they attended the self-contained classroom. 2) Staffing issues across both schools: It is imperative the schools verify that the impact of any given student or group of students transitioning from one environment to another will not overwhelm individual teachers or grade levels the subsequent year. However, lack of special educators, paraeducators, or other staffing issues was considered an insufficient reason to prevent moving students back to their neighborhood schools (i.e., no student was left in a special class placement because the neighborhood school did not have sufficient resources). This is a discussion among the building administrators of the individual schools and district facilitators (not the special education teachers). Finally, 3) What transitional assistance the next school year by district facilitator/coordinator should look like.

The two school teams need to develop a set of transitional IEP goals to scaffold the student into a new school/grade/placement, preferably with goals geared toward full student independence in the general education classroom. Additionally, there needs to be a conversation regarding how often a district facilitator/coordinator explicitly checks in on transitioned students at their new school. 


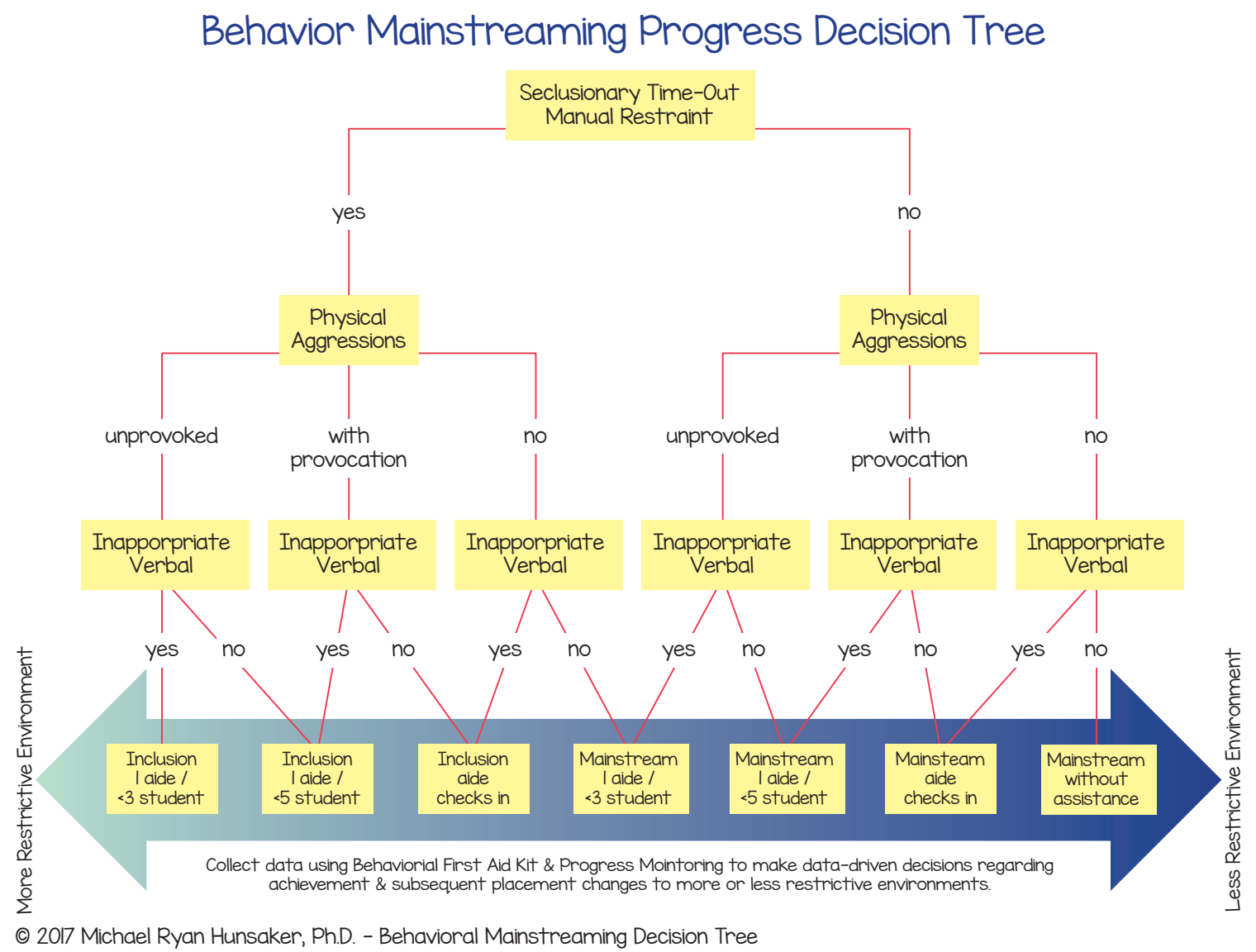

Figure 6: Behavioral Mainstreaming Decision Tree. The Behavioral Mainstreaming Decision Tree is a visual depiction of the datadriven decision making process used to identify candidates for transition from self-contained special education to general education with part time special education/Resource services placements. Data regarding behavioral performance in self contained and general education classroom are collected and taken into account. Biweekly meetings are held to determine if student needs more or less restrictive environments. Along the bottom are the spectrum of restrictive environments ranging from inclusion with an aide on the left to independent mainstream access to the general education classroom on the right. 


\section{Results}

\subsection{Student Allocation Using Academic Mainstreaming Decision Tree}

To determine the validity of manually placing students into groups to receive mainstreaming or to receive social inclusion, a computational analysis was undertaken. This analysis used the results of the regression trees above and used those data structures to sort students into 2 groups, Mainstreaming and Inclusion. In some computational analyses the computer returned a third group of outliers that were "higher" than predicted. These were labeled GenEd for general education simply for display purposes.

In order to quantify the accuracy of the clustering approaches, a machine learning classification algorithm was employed. This method, called Support Vector Machines, is designed to identify an optimal separation among groups or classes of data.

The algorithm was trained by using different numbers of data points (students) to train the algorithm and testing it with the rest of the datasets. This analysis confirms the correctness of the heatmaps as well as trains a computer to discriminate among the 3 classes of students, allowing for unknown students' data to be input and a classification be elucidated. Based on preliminary exploratory analyses, a linear kernel resulted in the most accurate sorting of students. Effort was taken to avoid over-fitting the data.

$\mathrm{K}$ means cross validation was used as a training and evaluation metric for the Support Vector Machine. In k-fold cross-validation, the original sample is randomly partitioned into $\mathrm{k}$ equal sized subsamples. Of the $\mathrm{k}$ subsamples, a single subsample is retained as the validation data for testing the model, and the remaining $\mathrm{k}-1$ subsamples are used as training data. $\mathrm{K}$ means cross validation with $\mathrm{K}=30,20,10,5$, and 3 were used to evaluate the efficacy of the algorithm. As such, 30-fold cross validation uses a smaller training set than a 10- or 5-fold cross validation ( 3 vs 10 and 20 respectively).

The $e 1071$ package was used to implement the support vector machine algorithm. To train the classifier the code was (Replicated 1000 times without replacement): 


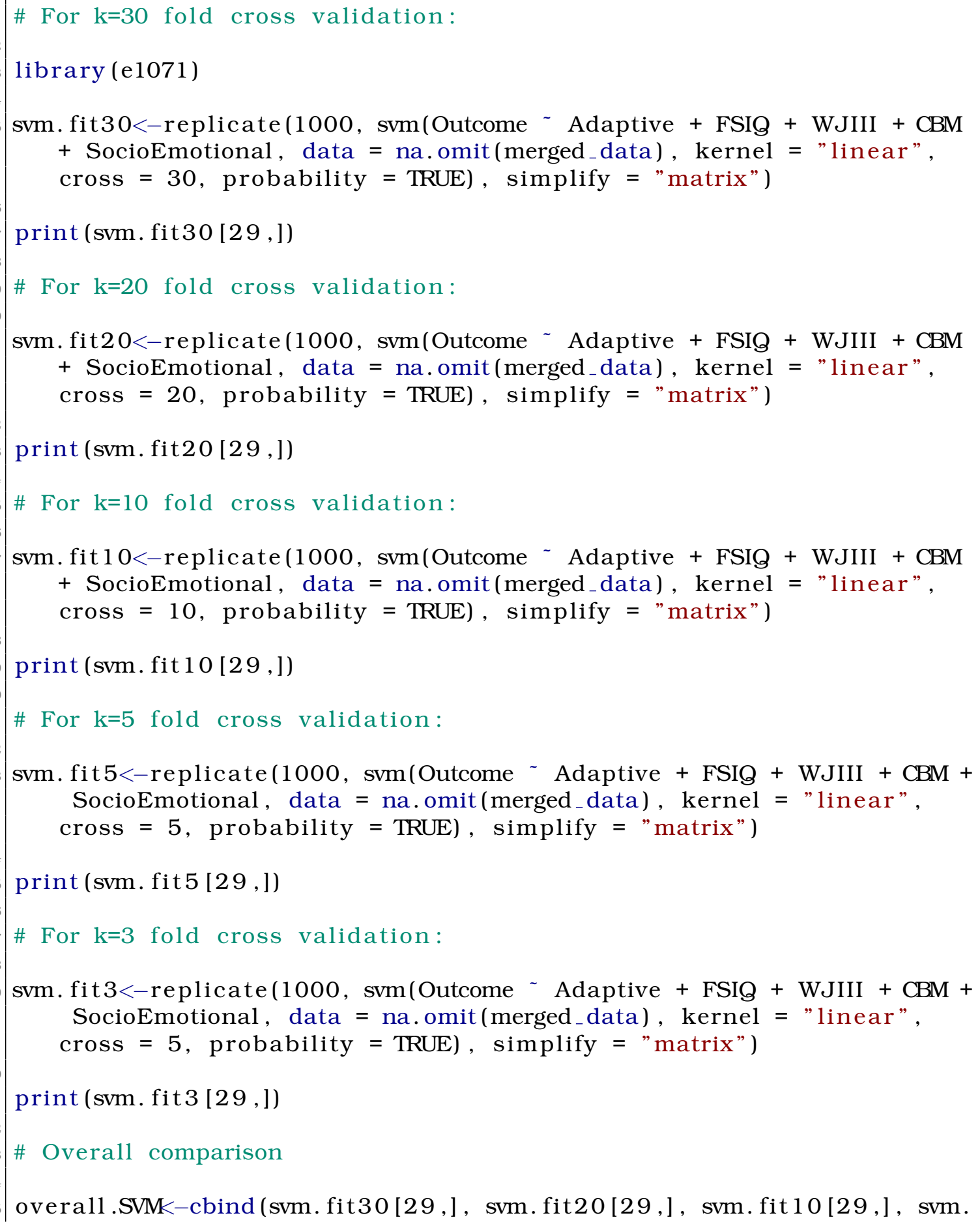


fit5[29,], svm. fit3 [29,])

colnames ( overall)<-c("svm. fit 30 ", "svm. fit20", "svm.fit 10 ", "svm.fit5", "svm.fit3")

Note in Table 4 that the classifier misclassified one (1) General Education student as Mainstreaming and zero (0) as inclusion. Three (3) inclusion students were mis-classified as needing mainstreaming and zero (0) as needing fast-tracking into the general education classroom. Three (3) Mainstreaming students were misclassified as General Education and 2 were misclassified as requiring inclusion. These data are important because they demonstrate the algorithms are optimistic, erring on the side of moving the student to a less restrictive environment rather than favoring more restrictive environments. Also, these data provide computational support for classroom decisions undertaken using the data from these analyses, which was to favor moving students into less restrictive environments as soon as they were approaching "ready", rather than waiting until everyone was certain the student or multiple students were ready and would succeed (this is analogous to the zone of proximal development; $c f$. , Zaretskii, 2009). Efficacy of the K-means classifier across multiple runs are shown in Fig 7.

An independent analysis taking the raw data used by the Regression Tree algorithm but using a different clustering algorithm was also performed. This analysis was performed using the heatmap. 2 library in the R statistical computing package. Preliminary analyses evaluated the data school by school, but there were no differences from the analyses using the omnibus dataset. So to preserve rigor, we only report the grouped data. The results of these analyses were heatmaps that showed similarities among students as well as similarities among factors.

Once the heatmap. 2 code was executed, the resulting hierarchical clustering-based visualizations were saved to file and remained unaltered. A deliberate choice was made to not cut the heatmaps or post process them for the sake of clarity.

The heatmap. 2 code for a combination of the four schools (8 classrooms):

library (heatmap. 2) 


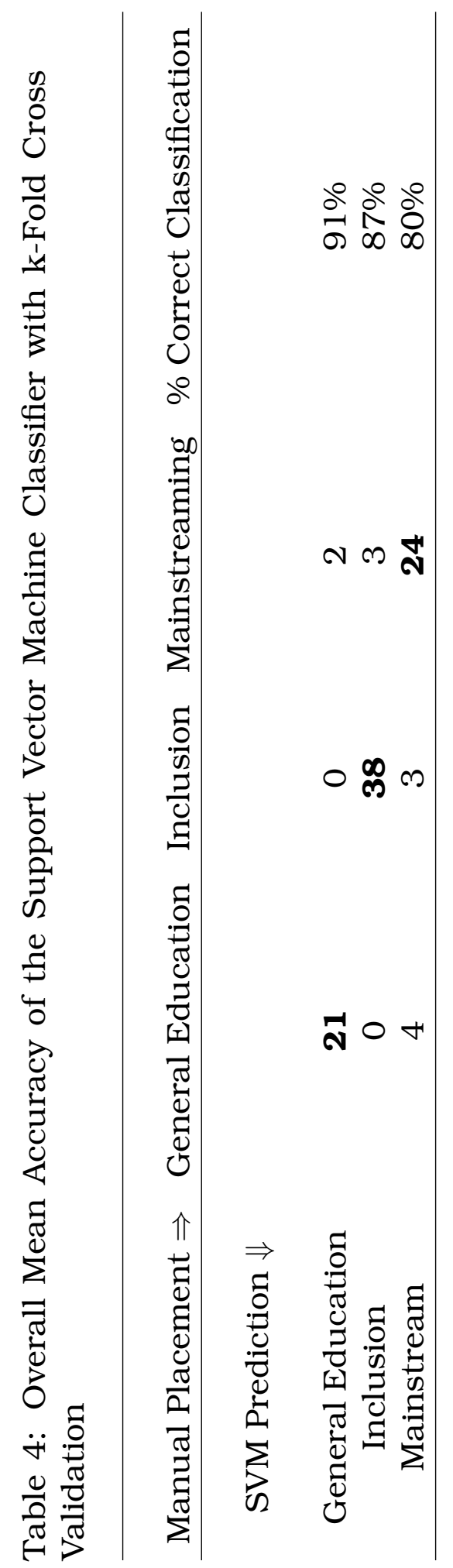

37

Accepted for Publication in "The European Journal of Education Studies" 

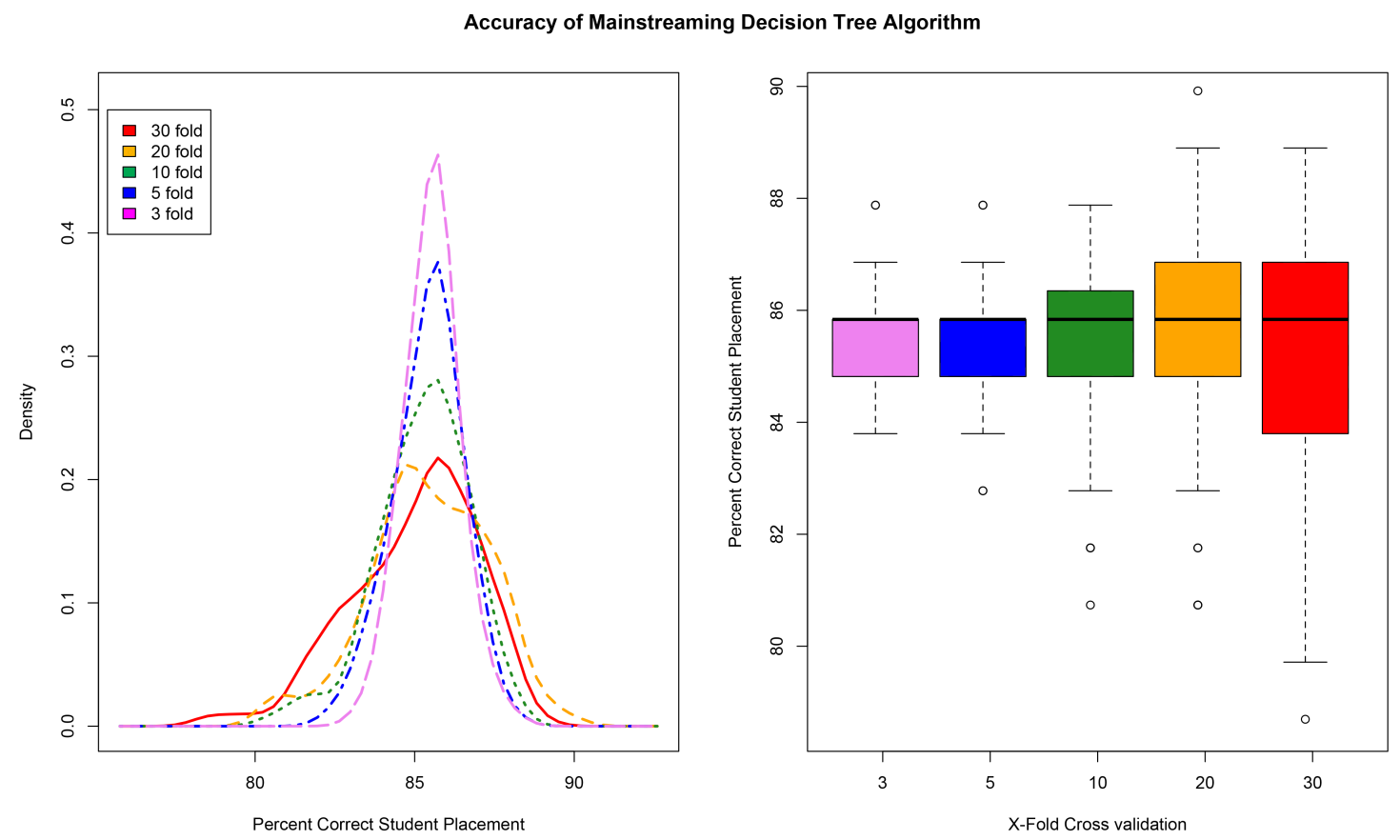

Figure 7: Overall Predictive Validity of the Academic Mainstreaming Decision Tree The plot on the left shows the probability density of each support vector machine prediction trained by K-fold cross validation. As can be seen, the 3 and 5 fold outperformed the other values for consistency, showing the sharpest peak. For clarity, the plot on the right contains each of the 1000 training sessions for the $k$-fold cross validation and are presented as Tukey boxplots with the 1.5 interquartile range (IQR) as the whiskers. The outlying data points were not removed. For all $k$-fold cross validations, the mean accuracy was similar, but the spread among the data points increased with the number of $k$-folds used. 


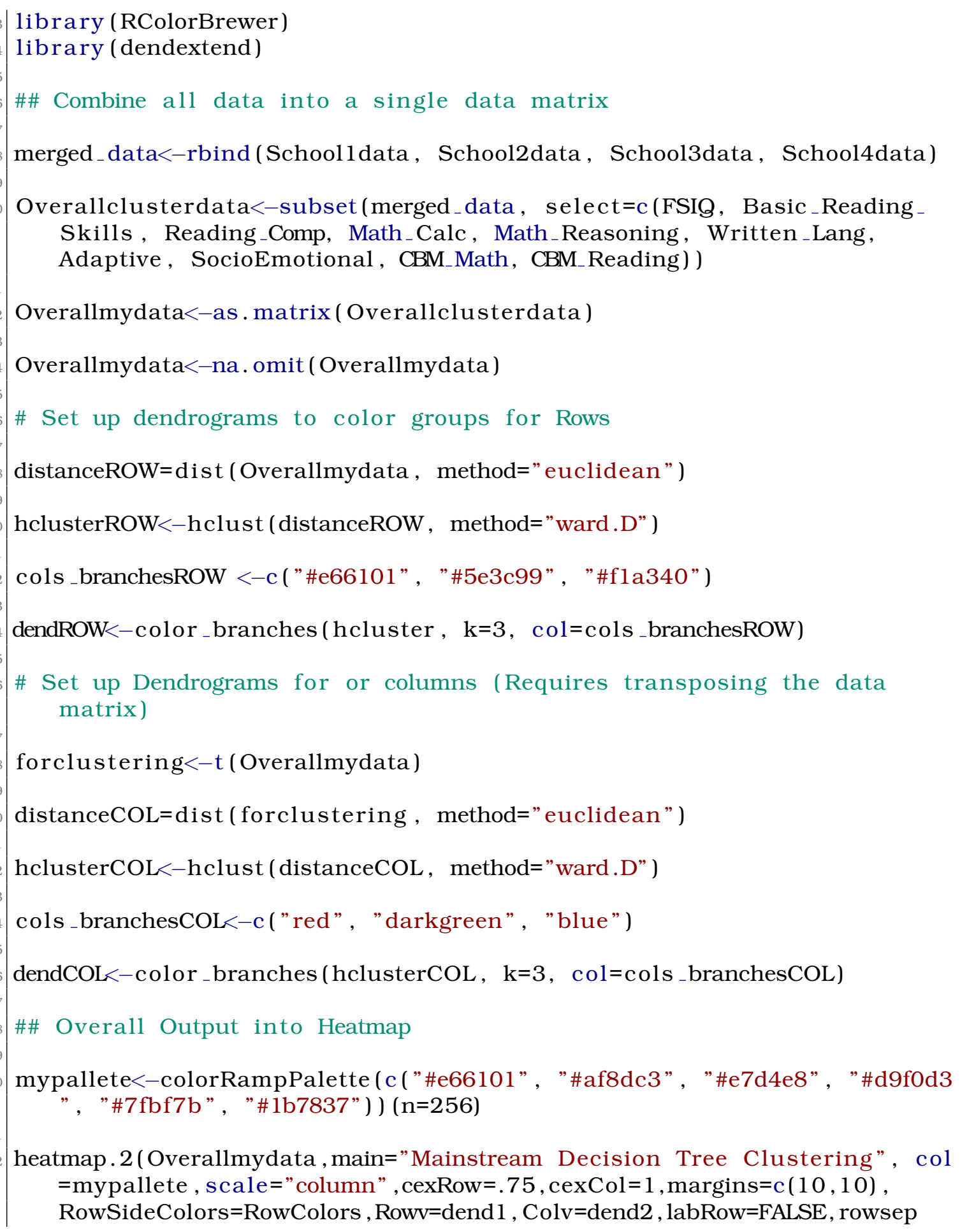


$=1: 100$, colsep $=1: 10$, sepcol $=$ "white, , sepwidth $=c(.015, .025)$, trace $="$

none", add. $\operatorname{expr}=\mathrm{c}($ abline $(\mathrm{h}=\mathrm{c}(67.4,23.4), \mathrm{lwd}=4, \mathrm{col}=$ "white" $)$, abline $(v=c(3.5,5.5,6.5,8.5), \quad l w d=4, \quad$ col="white" $)))$

The data presented in the heatmap in Figure 8 that there was less correct classification of students designated for mainstreaming or inclusion compared to Academic Mainstreaming Decision Tree (as evidenced in Table 4). Interestingly, one can also see the Cognitive factors were separated from the academic factors, and CBM measurements were included as cognitive, rather than academic factors. Interesting to note, the students misclassified by the SVM analyses were misidentified the same way using this clustering algorithm. Looking at the patterns of data, it appears that CBM performance was more influential during the clustering than the SVM analyses, likely leading to the disparate clustering of students.

Notwithstanding these differences, the data from these computational analyses all support the use of the Academic Mainstreaming Decision Tree by reaching similar conclusions as to student allocation or classification as the Academic Mainstreaming Decision Tree using a converging method, 


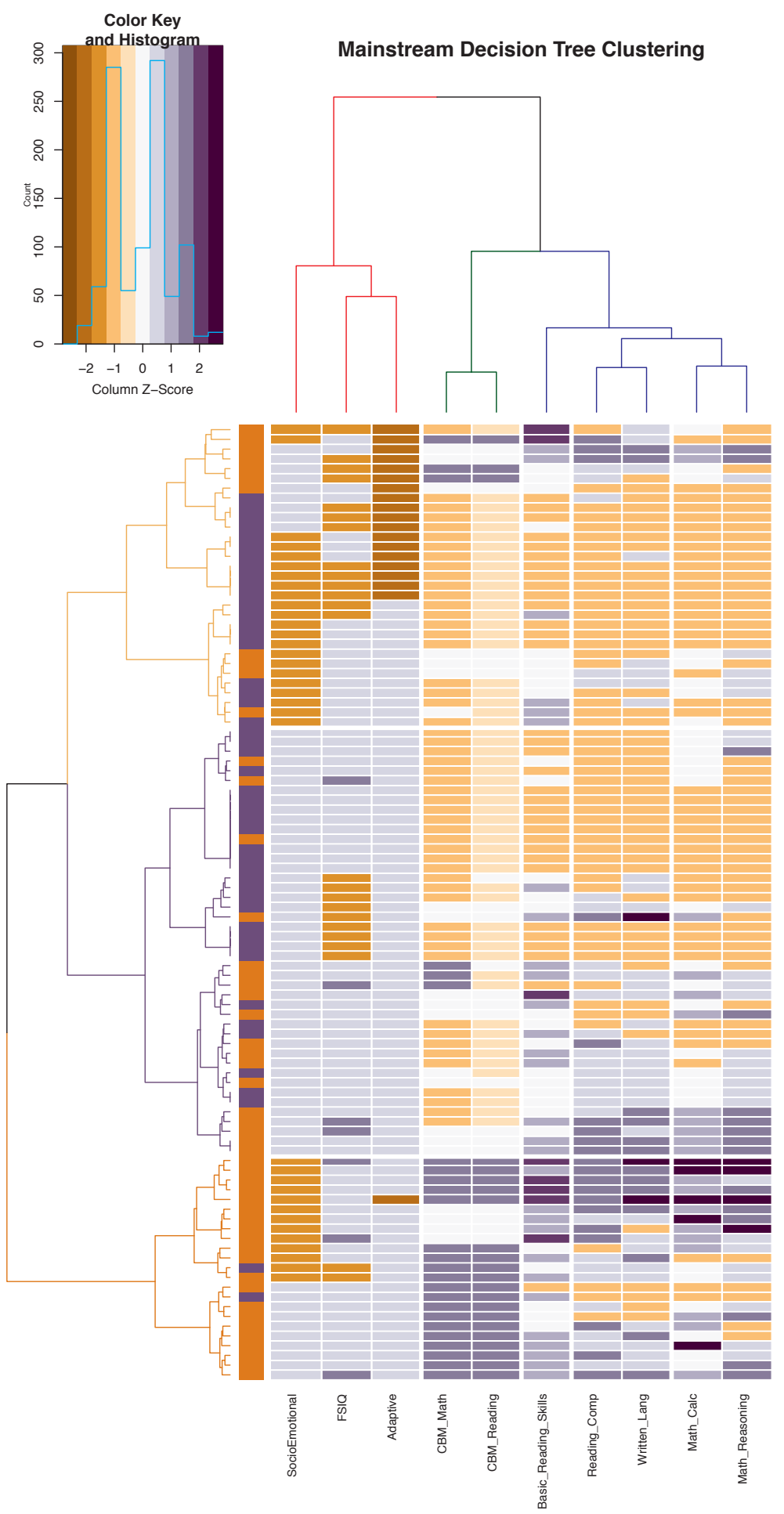

41

Accepted for Publication in "The European Journal of Education Studies" 
Figure 8: Unsupervised Hierarchal Clustering. When all data are put together and allowed to self assemble using a greedy algorithm, three groups emerge. Along the left, the bottom, dark orange cluster corresponds to students that successfully entered a general education placement. The top, light orange cluster corresponds to students that were assigned to $>75 \%$ mainstreaming. The middle purple cluster are students that were allocated to a group receiving social inclusion. Along the top, the nonacademic factors clustered together as highly related and predictive of student placement. The green cluster corresponds to CBM measures, and the purple cluster correspond to the WJ-III NU factors, with reading/writing skills separated from math skills.

\subsection{Results - 2015-2016}

In the first year / pilot implementation, we identified 20 students (17 male, 3 female - the ratio roughly matched the gender demographics in these special education classrooms) as candidates for transition from the self-contained classroom into a general education with part time special education placement using the Academic Mainstreaming Decision Tree. Ten (10) of these students were classified as Autism, six (6) as Significant Learning Disabled (SLD), two (2) as Speech and Language Impairment (SLI), one (1) as Emotional Disturbance (ED)and one (1) as Other Health Impairment (OHI). Students identified as candidates for transition from self contained special education to general education placements ranged from $1^{\text {st }}$ through $5^{\text {th }}$ grade. $6^{\text {th }}$ grade students were not included in the preliminary implementation.

The mean adaptive composite standard score for these 20 students was SS $73.2+/-10.37$ (standard deviation - SD). The mean full scale IQ standard score was SS $93.3+/-10.34$ SD. The mean WJ-III NU academic achievement standard scores were as follows: Reading Skills 86.72 +/- 16.1 SD ; Reading Comprehension 80.21 +/- 15 SD ; Math Calculation 79.1 +/- 24.3 SD; Math Reasoning 78.1 +/- 21 SD; Broad Writing $74.89+/-12.92 \mathrm{SD}$.

Overall, of the 20 students, 5 of the 20 candidate students had 
anxiety or BSI T scores T $>70$ on the BASC, Connor's, or CBCL (25\%). The 20 students that were identified as potential candidates based on these scores from their special education files appeared to be a clear outlying group when compared to their peers across all measures.

Once identified, these students were observed for two weeks to identify any behavioral issues that could potentially impede access to the general education curriculum. At the same time, students were receiving in-class academic placement examinations to group or classify them into appropriate learning levels within their self-contained classroom. Many of these students were identified as already being able to access (or master) nearly all levels of the special education curriculum at the beginning of the year. All the students in the classroom were also administered district CBM benchmarks and many of the curriculum based measures listed in Table 1. Based upon success on these measures students were considered candidates for transition out of the self-contained special education classroom.

Profiles of all the students that were candidates for a transition from a self-contained special education classroom to the general education placement are presented in Table 5.

Four $5^{\text {th }}$ grade students successfully transitioned from a selfcontained special education placement to a general education with part time special education services placement. One $5^{\text {th }}$ grade student finished the year spending $>75 \%$ time in the general education classroom. The IEP team proposed a transition during the next school year.

Two $4^{\text {th }}$ grade students successfully transitioned from a selfcontained special education placement to a general education with part time special education services placement. One $4^{\text {th }}$ grade student was unable to access the grade level CBM and was unable to transition into the general education environment. One $4^{\text {th }}$ grade student was unable to make this transition and requested they return to the self-contained classroom. One $4^{\text {th }}$ grade student demonstrated extreme behaviors in public spaces that prohibited access to the general education classroom. The latter two of these students began a program of explicit academic and social skills training in preparation for the upcoming school year.

Two $3^{\text {rd }}$ grade students were receiving access to the resource classroom rather than the general education classroom as this was considered the most appropriate placement for these students to learn aca- 
demic skills necessary for an eventual transition into the general education classroom. Two more $3^{\text {rd }}$ grade students successfully transitioned from a self-contained special education placement to a general education with part time special education services placement. One $3^{\text {rd }}$ grade student was unable to access the grade level CBM and was unable to transition to the general education environment.

One $2^{\text {nd }}$ grade student successfully transitioned from a selfcontained special education placement to a general education with part time special education services placement. Another two $2^{\text {nd }}$ grade students were able to handle between $50-75 \%$ time in the general education classroom and efforts were underway to explicitly teach academic and adaptive skills to them so they may pursue an eventual placement in the general education setting in subsequent years.

One $1^{\text {st }}$ student successfully transitioned from a self-contained special education placement to a general education with part time special education services placement. Another $1^{\text {st }}$ grade student was able to handle between 50-75\% time in the general education classroom. The IEP team proposed a transition during the next school year. 


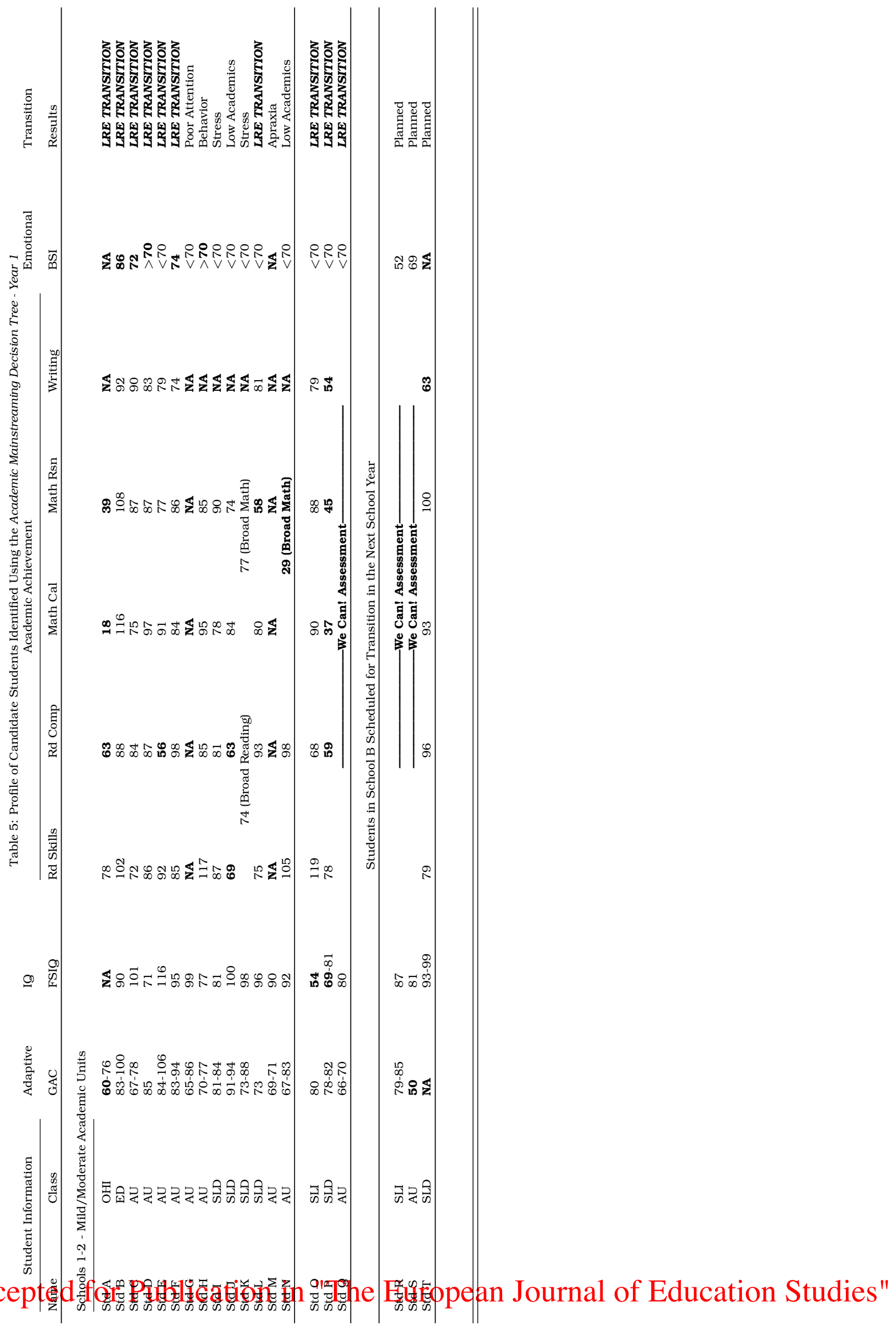




\subsection{Results - 2016-2017}

In the second year of this pilot implementation, we identified 53 students (37 male, 16 female - the ratio roughly matched the gender demographics in these special education classrooms) as candidates for transition from the academic self-contained classroom into a general education with part time special education placement using the Academic Mainstreaming Decision Tree. 24 of these students were classified as Autism (AU), 15 as Significant Learning Disabled (SLD), 4 as Speech and Language Impairment (SLI), 2 as Other Health Impairment (OHI) (though one of these was OHI for a medical diagnosis of autism but parent did not want the "autism" label attached to their student), 1 as Traumatic Brain Injury (TBI), 1 as Orthopedic Impairment (OI), 2 as Emotional Disturbance (ED), 2 as Intellectual Disability (ID), and 2 as Developmental Delay (DD). Students identified as candidates for transition from self contained special education to general education placements ranged from $1^{\text {st }}$ through $5^{\text {th }}$ grade. $6^{\text {th }}$ grade students were included in this second year implementation implementation.

The mean adaptive composite standard score for these 53 students was SS $76.12+/-15.45$ (standard deviation - SD). The mean full scale IQ standard score was SS 87.40 +/- 13.04 SD. The mean WJIII NU academic achievement standard scores were as follows: Reading Skills 89.88 +/- 17.20 SD ; Reading Comprehension 74.31 +/- 15.21 SD ; Math Calculation 88.11+/- 28.2 SD; Math Reasoning 72.98 +/- 19.71 SD; Broad Writing 76.98 +/- 14.81 SD.

Overall, of the 53 students, 12 of the candidate students had anxiety or BSI T scores T $>70$ on the BASC, Connor's, or Achenbach CBCL $(22.6 \%)$. The 53 students that were identified as potential candidates based on these scores from their special education files appeared to be a clear outlying group when compared to their peers across all measures.

Once identified, these students were observed for two weeks to identify any behavioral issues that could potentially impede access to the general education curriculum. At the same time, students were receiving in-class academic placement examinations to group or classify them into appropriate learning levels within their self-contained classroom. Many of these students were identified as already being able to access (or master) all levels of the special education curriculum at the beginning of the 
year. All the students in the classroom were also administered district benchmarks and many of the curriculum based measures listed in Table 1. Based upon success on these measures, students were considered candidates for transition out of the self-contained special education classroom.

Profiles of all the students that were candidates for a transition from a self-contained special education classroom to the general education placement are presented in Table 6 . For students carrying over across the first and second year of this pilot implementation, the alphabetical and numerical code are both presented in Table 6

\subsubsection{Academic Self Contained Cluster Units}

There were seven (7) $6^{\text {th }}$ grade student candidates. Four (4) $6^{\text {th }}$ grade students successfully transitioned from a self-contained special education placement to a general education with part time special education services placement. An additional 2 were able to spend $75-100 \%$ of the time in the general education classroom with minimal academic supports. One (1) required excessive behavioral supports in the general education classroom to spend more than $25 \%$ of their time out of the special education classroom.

There were thirteen (13) $5^{\text {th }}$ grade student candidates. Three (3) $5^{\text {th }}$ grade students successfully transitioned from a self-contained special education placement to a general education with part time special education services placement. Another 8 were able to access the general education classroom $50-75 \%$ of the time with minimal academic supports. Two (2) more were able to access the general education classroom $75 \%$ of the time when behavioral supports were present. There were five (5) $4^{\text {th }}$ grade student candidates.

One (1) $4^{\text {th }}$ grade student successfully transitioned from a selfcontained special education placement to a general education with part time special education services placement. The other 3 students were able to be in the general education classroom $50-75 \%$ of the time with minimal academic and behavioral supports. There were twelve (12) $3^{\text {rd }}$ grade student candidates.

Three (3) $3^{\text {rd }}$ grade students successfully transitioned from a selfcontained special education placement to a general education with part 
time special education services placement. Another 7 students were able to spend $50-75 \%$ of the time in the general education classroom with minimal academic supports in place. The other 2 students required excessive behavioral supports to spend more than $25 \%$ of the day in the general education classroom.

There were thirteen (13) $2^{\text {nd }}$ grade student candidates. Four (4) $2^{\text {nd }}$ grade students successfully transitioned from a self-contained special education placement to a general education with part time special education services placement. An additional 2 were able to spend $75-100 \%$ of the time in the general education classroom with minimal supports and efforts were underway to explicitly teach academic and adaptive skills to them so they may pursue an eventual placement in the general education setting in subsequent years.

Six (6) students were able to access $50-75 \%$ of the day in the general education classroom if significant academic supports were provided. One (1) student requires extensive 1:1 behavioral support in the general education classroom and was mainstreamed $100 \%$ of the time, but was able to complete academic tasks. There were three (3) $1^{\text {st }}$ grade student candidate. One (1) $1^{\text {st }}$ grade student successfully transitioned from a selfcontained special education placement to a general education with part time special education services placement. The other 2 students required academic supports to spend $50 \%$ of the day in the general education classroom.

\subsubsection{Students in Other types of Unit Classrooms}

In addition to the academic cluster units, this model was extended to SEL/behavior unit and to severe/ID cluster units.

In all, 26 students were identified as candidates for mainstreaming based on the Behavioral Mainstreaming Decision Tree. Of those, 9 were able to access the mainstream classroom $75-100 \%$ of the day and were able to successfully transition to a general education with part time special education placement. The other 17 were able to be in mainstreaming $25-50 \%$ of the time but lacked the SocioEmotional skills to obtain independence during the school year.

For the Life Skills/severe/ID cluster units, 9 students were identified as candidates for mainstreaming based on teacher report of CBM 
performance. All 9 of these students were able to access the mainstream curriculum and were able to transition to a general education with part time special education placement.

For diagnostic kindergarten students (academic self contained kindergarten), 7 candidate students were identified. Of these 7,3 were able to access the mainstream kindergarten classroom $>50 \%$ of the time and were transitioned to a general education classroom with part time special education. The other 4 students had not yet developed the self regulation skills to reliably spend $>25 \%$ of their day in the mainstream setting.

Overall, of 94 candidate students across all special education settings, 41 were able to successfully transition into a general education with part time special education services placement for this coming year. In other words, $43 \%$ of identified candidate students were able to successfully transition from full time to part time special education. An additional 10 were able to access a less restrictive unit classroom (e.g., Severe to Mild/Moderate cluster unit or SEL/behavior unit to Mild/Moderate cluster unit). This meant that $54 \%$ of identified candidate students were able to access a less restrictive environment as defined by IDEIA. 


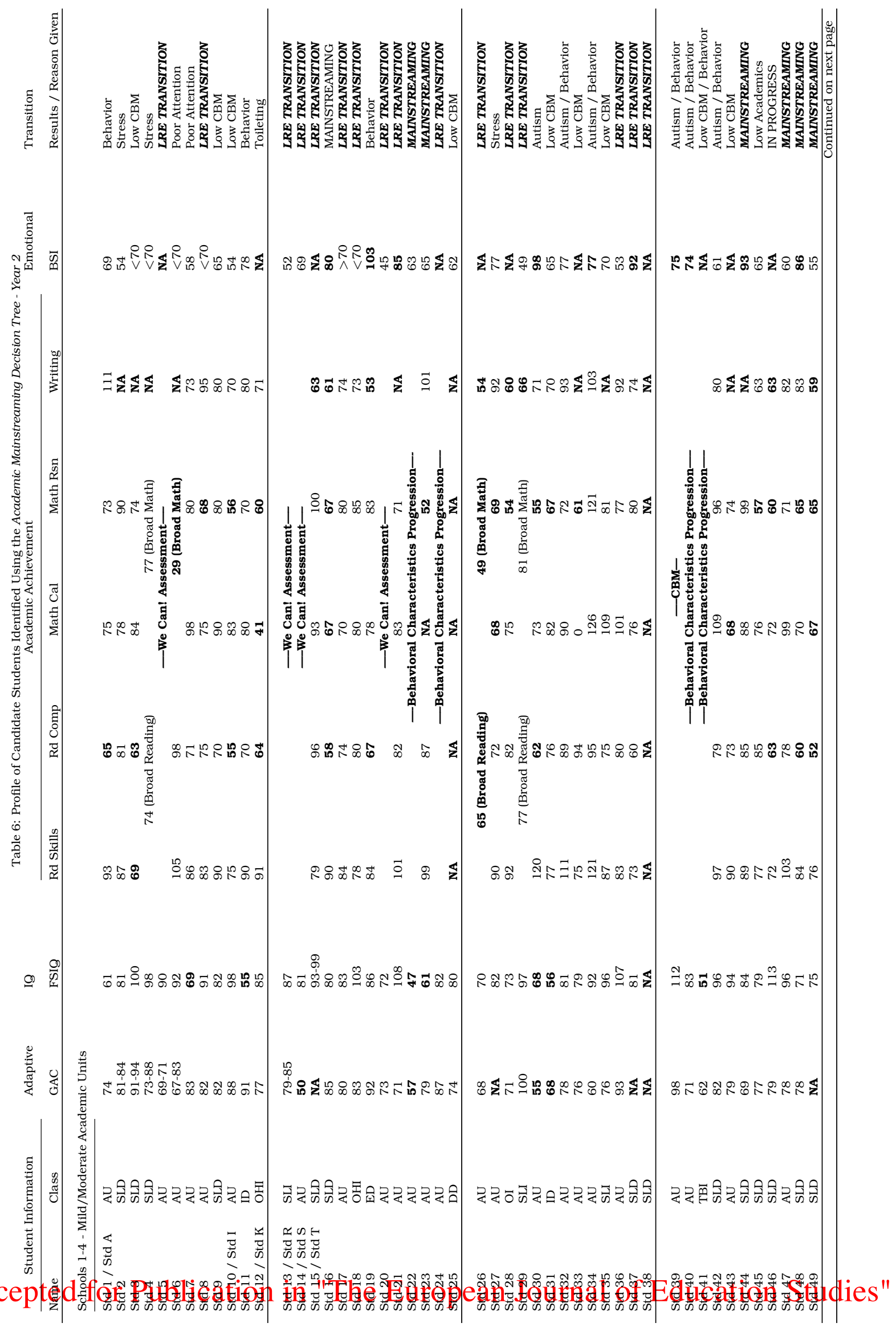




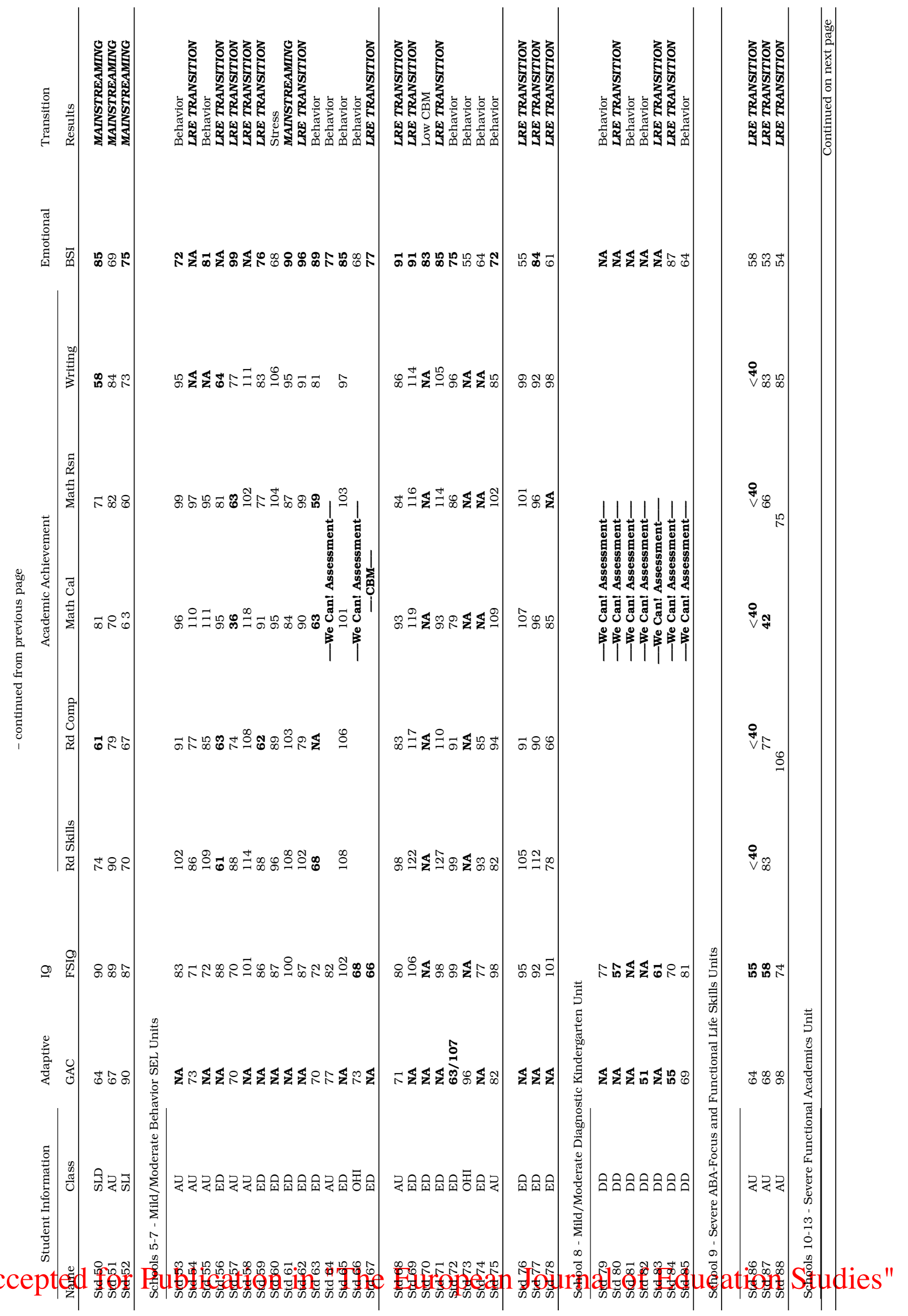




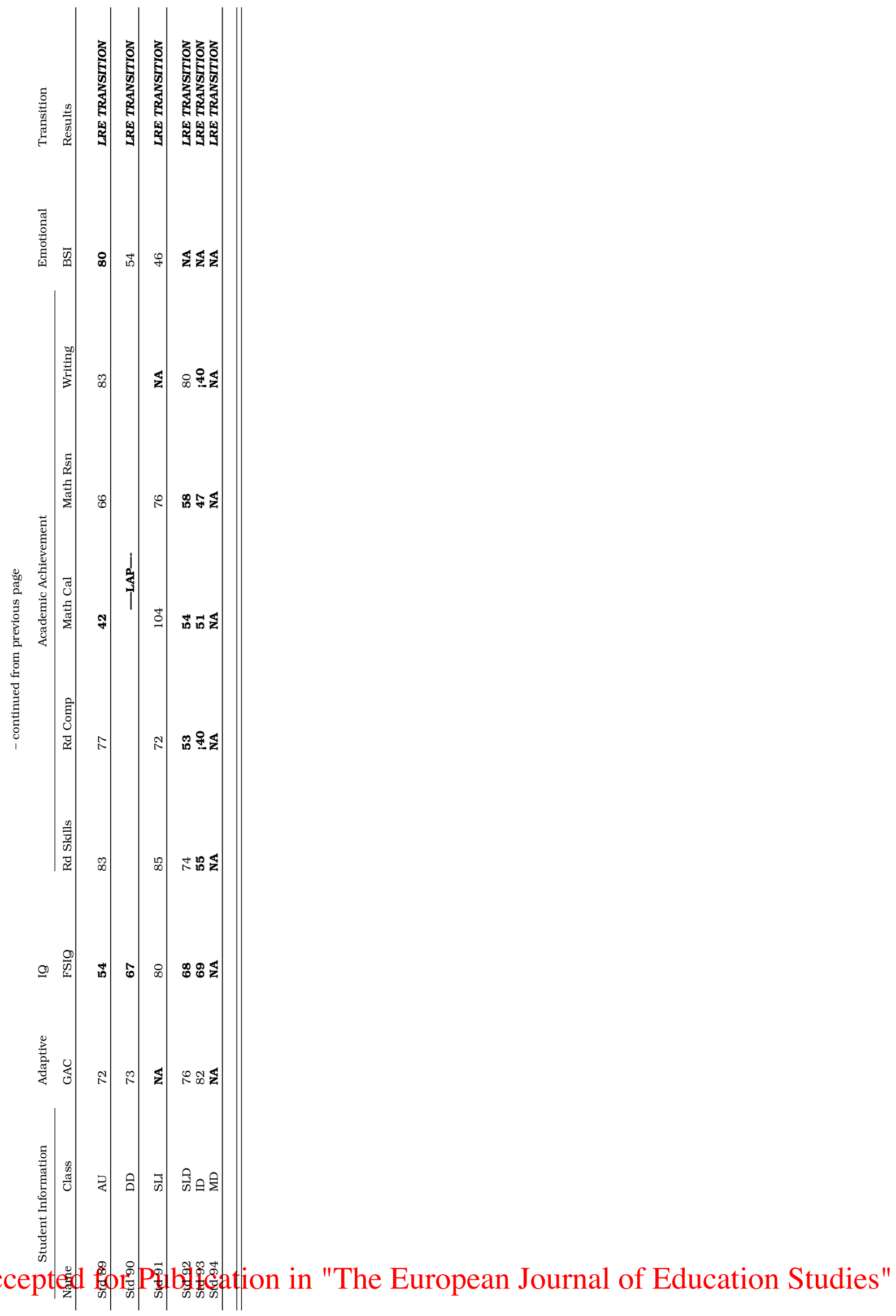




\section{Discussion}

\subsection{Implications}

\subsubsection{Year One}

Of the 20 candidates identified by the Academic Mainstreaming Decision Tree, 10 Students successfully made the transition to a general education placement (50\%) during the school year, and 3 more were scheduled to make a similar transition relatively early in the next school year (15\%); making for a total of 65\% transition success based on the first year limited implementation of the Mainstreaming Process. These numbers supported an extension of this pilot transenvironmental programming implementation given we were able to use our mainstreaming tools to identify the potential candidates for mainstreaming early.

\subsubsection{Year Two}

Of the 53 candidates identified by the Academic Mainstreaming Decision Tree, 16 Students successfully made the transition to a general education placement (30\%) during the school year, and 5 more were scheduled to make a similar transition relatively early in the next school year (10\%); making for a total of $40 \%$ transition success based on the second year implementation of the Mainstreaming Process. Three (3) of 7 kindergarten students in Diagnostic Kindergartens were able to access the general education kindergarten as well.

These numbers supported an extension of this transenvironmental programming implementation district wide. When all self-contained classrooms were evaluated, an additional 26 students in SEL classrooms were identified as candidates for mainstreaming based on the Behavioral Mainstreaming Decision Tree. Of those, 9 were able to access the mainstream classroom $75-100 \%$ of the day and were able to successfully transition to a general education with part time special education placement. The other 17 were able to be in mainstreaming $25-50 \%$ of the time but lacked the SocioEmotional skills to obtain independence during the school year.

For the Life Skills/severe/ID cluster units, 9 students were iden- 
tified as candidates for mainstreaming based on teacher report of CBM performance. All 9 (100\%) of these students were able to access the mainstream curriculum and were able to transition to a general education with part time special education placement.

For diagnostic kindergarten students (academic self contained kindergarten), 7 candidate students were identified. Of these 7,3 were able to access the mainstream kindergarten classroom $>50 \%$ of the time and were transitioned to a general education classroom with part time special education. The other 4 students had not yet developed the self regulation skills to reliably spend $>25 \%$ of their day in the mainstream setting.

Overall, 94 candidate students across all special education settings were identified as candidates, and 41 were able to successfully transition into a general education with part time special education services placement for this coming year. In other words, $43 \%$ of identified candidate students were able to successfully transition from full time to part time special education.

An additional 10 were able to access a less restrictive unit classroom (e.g., Severe to Mild/Moderate cluster unit or SEL/behavior unit to Mild/Moderate cluster unit). This meant that $54 \%$ of identified candidate students were able to access a less restrictive environment as defined by IDEIA.

\subsubsection{Computational Analysis}

Computationally, the methods provided in this manuscript demonstrate all the information needed for moving students into the appropriate LRE are available in the special education evaluation. That means all data qualified for special education have all the data needed to determine LRE available at the moment they qualify for special education services.

The recursive partitioning algorithm was sufficient to sort students into reasonable groups that could easily be manually sorted into LRE groups using the Academic Mainstreaming Decision Tree. Intriguingly, the results of recursive partitioning with or without academic scores present resulted in highly similar sorting, there were just a greater number of categories when academic testing was included. 
For hierarchal clustering, the algorithm reached highly similar conclusions as the regression trees from the recursive partitioning. There was a group of outliers that did not appear like students receiving special education that were labeled GenEd, and a group of mainstreaming and inclusion students. Both the clustering and partitioning methods were conservative in that they erred in sorting students in a slightly more restrictive environment than the one the student was eventually placed in.

Most importantly, when the validity of the system was formally assessed using a support vector machine algorithm with K-means cross validation, the computational methods were $85 \%$ accurate. This means $85 \%$ of the students were placed in the same LRE as when they were manually sorted. It would be preferable to have $>90 \%$ correct sorting, but we view this computational sorting as a preliminary step that must be followed up by manual scrutiny.

Of additional interest but not formally assessed in this report was that the accuracy of classifying students increases with the addition of data into the classification matrix. When a check was done by importing the year 1 data into the year 2 matrix, there was more accurate classification of year 1 student. Future directions should include increasing the aunt of data available to the classifier to perhaps increase predictive validity beyond the present $84-85 \%$.

\subsubsection{Overall Implications}

Of particular interest was the fact that by enriching the candidate pool of students to those empirically predicted to show success in the general education classroom, the task of mainstreaming for teachers becomes much less overwhelming so far as the day to day logistics are concerned. Of the 3 classes participating in the pipeline during the first year, one classroom had 4 of their 15 students $(27 \%)$ in mainstreaming for some portion of the day. Another class had 6 of 20 students $(30 \%)$ in the mainstream classroom for the entire day. The third had 3 of 12 students (25\%) in the mainstream classroom for a significant portion of the day. One implication of these numbers was that the special education teachers had a significantly lightened load so far as teaching requirements. This reduced teaching load provided opportunities to work more directly with the remaining students in the classroom without having to accommodate 
for the instructional needs of a group of students performing at a higher academic level than the rest of the classroom. When this was extended to include the second year, a similar 25-30\% of students mainstreaming was accomplished. Across the 8 classrooms, there were 102 total students, of whom 53 were identified as potential mainstreaming candidates (51\%). A total of 29 students participated in full day mainstreaming $(28 \%)$, with an additional 15 accessing mainstream curriculum for either language arts or math (for a total of $42 \%$ ).

Not emphasized earlier this manuscript was one additional utility of the Academic Mainstreaming Decision Tree and Behavioral Mainstreaming Decision Tree for identifying social inclusion placement as well as mainstreaming placement for single subjects. Beyond the students that transitioned, an additional 6 students received access to ELA or mathematics instruction based on placement decisions motivated by the Academic Mainstreaming Decision Tree. Full mainstreaming was not pursued with these students based on profound achievement gaps for the other subject compared to general education peer groups.

\subsection{Limitations}

One limitation of this pilot implementation was the relatively low number of candidate students identified be the Academic Mainstreaming Decision Tree during year 1 . This pilot implementation of the Mainstreaming Process was only slated for two classrooms and a third came on board mid-way through the year. As such, only 20 students were identified as candidates for transition from a self-contained special education placement into a general education placement. However, these 20 students were from a total special education population of 62 students $(32 \%)$ in self-contained academics classrooms, the data appear to show some predictive value. However, when we moved to a district-wide implementation we were able to identify a greater number of candidate students, a lower percentage were able to be successful in a mainstreaming environment We interpret this as the pilot implementation being carried out at schools with an already recognized need for a transenvironmental programming pipeline, so it served as an enriched sample. When the model was extended, the data reflected a more realistic situation wherein $28 \%$ rather than $50 \%$ of candidate students were able to access educational place- 
ments in general education classrooms.

Additionally, as can be seen from Table 4 and Table 5 there were missing Academic Achievement data that made identifying candidate students difficult. The best way to remedy this deficiency moving forward will be to verify special education files have all the data necessary for the Academic Mainstreaming Decision Tree at the beginning of the year and collecting any "missing" assessments early in the year, during the first quarter.

Finally, there was always difficulty in identifying personnel to assist with inclusion and mainstreaming. If students need more restrictive environments as an initial mainstreaming option, then there will likely be a personnel requirement. Methods and supports remain to be developed to mitigate the effect of a lack of personnel. With the presently reported implementation, preferential focus was placed on transitioning students that had the lowest need of support personnel. The other students had to be put into small groups for mainstreaming or inclusion, and this deindividualized the process somewhat, resulting in less than optimal mainstreaming outcomes.

\subsection{Next Steps}

Subsequent analyses are necessary with larger datasets to determine if the computational methods underlying the Academic Mainstreaming Decision Tree could be automated and centralized in an on-line, cloud based repository. The long term utility of such an on-line system this would be a quick screen for LRE that administrators and IEP teams could use to guide placement decisions once the IEP goals are outlined. Such a system would also facilitate data-based decision making by rural LEA that lack sufficient data to develop computational analyses to predict student success. Giving them access to a broad, diverse data set may help the teams in designing instructional programs for individual students.

Development of such a database would require access to special education data that crosses socioeconomic, gender, and racial divides to guarantee the system is maximally unbiased. Implementation would also require a system capable of protecting identifiable information from any uploaded data to prevent inadvertent FERPA or HIPAA violations. However, these would be possible with a RedCap, mySQL or SAS-based 
database with a Java-based front-end to query the database for comparison data and any actual computations could be carried out either in a cloud-based system or on a local computer.

\subsection{Conclusions}

Overall, the Academic Mainstreaming Decision Tree, Behavioral Mainstreaming Decision Tree and associated Mainstreaming Process proved to be useful transenvironmental programming tools for the self-contained special education classrooms they were tested in. These methods were reasonably simple and straightforward to administer. We feel that these specific processes may prove useful for facilitating the transition of students in self-contained special education placements into the general education population. Our implementation resulted in an overall transition success of $50 \%$ of identified candidate students the first year and $43 \%$ for the second year.

An additional benefit of the Academic Mainstreaming Decision Tree was that it was inherently conservative with regards to student behavior and coping skills. This was accomplished by using raw evaluation data paired with unbiased computational analyses to generate decision making methods. By taking Adaptive Function as the primary consideration, students that have difficulty in coping with novel situations were started in more restrictive mainstreaming environments than those that showed higher adaptive composite scores. Upon demonstrating success in these more restrictive environments, the supports were faded and the student moved to increasingly less restrictive environments. In a similar vein, the final step of the Academic Mainstreaming Decision Tree was to account for elevated behavioral problems or heightened anxiety that may interfere with academic and/or behavioral success in the general education classroom by explicitly adding scaffolds and supports into placement decisions.

Based upon the current results, the pilot implementation of the Mainstreaming Process was successful in that between $40-50 \%$ of the identified candidate students were able to make a transition from a highly restrictive classroom placement (self-contained special education classes) to a much less restrictive placement, namely general education with part time special education services. This means that these students went 
from receiving 6.5 hours (390 minutes) of daily special education services to receiving between 30-90 minutes of special education services daily. An additional $10 \%$ were able to access a less restrictive self-contained unit placement

The implications of this pipeline are clear. For the cascading system of special education service provision to work, efforts need to be made to challenge students and offer the opportunity for students to move toward less restrictive placements. This Academic Mainstreaming Decision Tree, Behavioral Mainstreaming Decision Tree, and Mainstreaming Process are two tools that may facilitate such a transition.

\section{References}

Anderson-Inman, L. (1987). Consistency of performance across classrooms: Instructional materials versus setting as influencing variables. The Journal of Special Education, 21(2), 9-29.

Angkustsiri, K., Leckliter, I., Tartaglia, N., Beaton, E. A., Enriquez, J., \& Simon, T. J. (2012). An examination of the relationship of anxiety and intelligence to adaptive functioning in children with chromosome 22q11. 2 deletion syndrome. Journal of Developmental and Behavioral Pediatrics, 33(9), 713.

Avramidis, E., Bayliss, P., \& Burden, R. (2000). A survey into mainstream teachers' attitudes towards the inclusion of children with special educational needs in the ordinary school in one local education authority. Educational Psychology, 20(2), 191-211.

Barbeau, E. B., Soulieres, I., Dawson, M., Zeffiro, T. A., \& Mottron, L. (2013). The level and nature of autistic intelligence iii: Inspection time. Journal of Abnormal Psychology, 122(1), 295.

Barnes, M. C., \& Gaines, T. (2015). Teachers' attitudes and perceptions of inclusion in relation to grade level and years of experience. Electronic Journal for Inclusive Education, 3(3), 3.

Bearden, C. E., van Erp, T. G., Monterosso, J. R., Simon, T. J., Glahn, D. C., Saleh, P. A., .. E Emanuel, B. S., et al. (2004). Regional brain abnormalities in 22q11. 2 deletion syndrome: Association with cognitive abilities and behavioral symptoms. Neurocase, 10(3), 198-206. 
Bedinim, L. A. (1990). Separate but equal? segregated programming for people with disabilities. Journal of Physical Education, Recreation \& Dance, 61(8), 40-44.

Biswas, A. B., \& Furniss, F. (2016). Cognitive phenotype and psychiatric disorder in 22q1 1. 2 deletion syndrome: A review. Research in Developmental Disabilities, 53, 242-257.

Brownell, M. T., Sindelar, P. T., Kiely, M. T., \& Danielson, L. C. (2010). Special education teacher quality and preparation: Exposing foundations, constructing a new model. Exceptional Children, 76(3), 357377.

Cauley, K. M., \& Jovanovich, D. (2006). Developing an effective transition program for students entering middle school or high school. The Clearing House: A Journal of Educational Strategies, Issues and Ideas, 80(1), 15-25.

Cohen, R. A. (2011). Yerkes-dodson law. In Encyclopedia of clinical neuropsychology (pp. 2737-2738). Springer.

Conway, R. N., \& Gow, L. (1988). Mainstreaming special class students with mild handicaps through group instruction. Remedial and Special Education, 9(5), 34-40.

Cooray, S. E., \& Bakala, A. (2005). Anxiety disorders in people with learning disabilities. Advances in Psychiatric Treatment, 11(5), 355-361.

Courchesne, V., Meilleur, A.-A. S., Poulin-Lord, M.-P., Dawson, M., \& Soulieres, I. (2015). Autistic children at risk of being underestimated: School-based pilot study of a strength-informed assessment. Molecular Autism, 6(1), 12.

Daniel, P. T. (1997). Educating students with disabilities in the least restrictive environment: A slippery slope for educators. Journal of Educational Administration, 35(5), 397-410.

Dawson, M., Soulieres, I., Gernsbacher, M. A., \& Mottron, L. (2007). The level and nature of autistic intelligence. Psychological Science, 18(8), 657-662. PMID: 17680932. doi:10.1111/j.1467-9280.2007.01954. x. eprint: http://dx.doi.org/10.1111/j.1467-9280.2007.01954.x

De Bildt, A., Sytema, S., Kraijer, D., Sparrow, S., \& Minderaa, R. (2005). Adaptive functioning and behaviour problems in relation to level of education in children and adolescents with intellectual disability. Journal of Intellectual Disability Research, 49(9), 672-681.

Dennis, M., Francis, D. J., Cirino, P. T., Schachar, R., Barnes, M. A., \& Fletcher, J. M. (2009). Why iq is not a covariate in cognitive studies of

60

Accepted for Publication in "The European Journal of Education Studies" 
neurodevelopmental disorders. Journal of the International Neuropsychological Society, 15(03), 331-343.

Ditterline, J., Banner, D., Oakland, T., \& Becton, D. (2008). Adaptive behavior profiles of students with disabilities. Journal of Applied School Psychology, 24(2), 191-208.

Dunn, K. E., \& Mulvenon, S. W. (2009). A critical review of research on formative assessment: The limited scientific evidence of the impact of formative assessment in education. Practical Assessment, Research \& Evaluation, 14(7), 1-11.

Edwards, O. W., \& Oakland, T. D. (2006). Factorial invariance of woodcock-johnson iii scores for african americans and caucasian americans. Journal of Psychoeducational Assessment, 24(4), 358366.

Ferri, B. A., \& Connor, D. J. (2005). Tools of exclusion: Race, disability, and (re) segregated education. Teachers College Record, 107(3), 453474.

Fisher, D., Frey, N., \& Thousand, J. (2003). What do special educators need to know and be prepared to do for inclusive schooling to work? Teacher Education and Special Education, 26(1), 42-50.

Fuchs, D. et al. (1994a). Best practices in school psychology: Peabody reintegration project.

Fuchs, D., Fernstrom, P., Scott, S., Fuchs, L., \& Vandermeer, L. (1994b). Classroom ecological inventory: A process for mainstreaming. Teaching Exceptional Children, 26(3), 11.

Fuchs, D., Fuchs, L. S., \& Fernstrom, P. (1992). Case-by-case reintegration of students with learning disabilities. The Elementary School Journal, 261-281.

Fuchs, D., Fuchs, L. S., \& Fernstrom, P. (1993). A conservative approach to special education reform: Mainstreaming through transenvironmental programming and curriculum-based measurement. American Educational Research Journal, 30(1), 149-177.

Fuchs, D., Mock, D., Morgan, P. L., \& Young, C. L. (2003). Responsivenessto-intervention: Definitions, evidence, and implications for the learning disabilities construct. Learning Disabilities Research \& Practice, 18(3), 157-171.

Gersten, R., \& Dimino, J. A. (2006). Rti (response to intervention): Rethinking special education for students with reading difficulties (yet again). Reading Research Buarterly, 41(1), 99-108. 
Gresham, F. M., \& Elliott, S. N. (1987). The relationship between adaptive behavior and social skills issues in definition and assessment. The Journal of Special Education, 21(1), 167-181.

Grondhuis, S. N., Lecavalier, L., Arnold, L. E., Handen, B. L., Scahill, L., McDougle, C. J., \& Aman, M. G. (2018). Differences in verbal and nonverbal iq test scores in children with autism spectrum disorder. Research in Autism Spectrum Disorders, 49, 47-55.

Group, P. H. W. (1991). Problems and promises in special education and related services for children and youth with emotional or behavioral disorders. Behavioral Disorders, 16(4), 299-313.

Heritage, M. (2007). Formative assessment: What do teachers need to know and do? Phi Delta Kappan, 89(2), 140.

Hocutt, A. M. (1996). Effectiveness of special education: Is placement the critical factor? The Future of Children, 77-102.

Hollenbeck, K., Tindal, G., \& Almond, P. (1998). Teachers' knowledge of accommodations as a validity issue in high-stakes testing. The Journal of Special Education, 32(3), 175-183.

Iwata, B. A., \& Bailey, J. S. (1974). Reward versus cost token systems: An analysis of the effects on students and teacher. Journal of Applied Behavior Analysis, 7(4), 567-576.

Johnson, D. R. (2005). Key provisions on transition: A comparison of idea 1997 and idea 2004. Career Development for Exceptional Individuals, 28(1), 60.

Kalaci, S. (2007). Students with autism left behind: No child left behind and the individuals with disabilities education act. Thomas Jefferson University Law Review. 30, 723.

Kauffman, J. M., Bantz, J., \& McCullough, J. (2002). Separate and better: A special public school class for students with emotional and behavioral disorders. Exceptionality, 10(3), 149-170.

Klotz, M. B., \& Nealis, L. (2005). The new idea: A summary of significant reforms. Retrieved July, 15, 2012.

Konold, T. R., Kush, J. C., \& Canivez, G. L. (1997). Factor replication of the wisc-iii in three independent samples of children receiving special education. Journal of Psychoeducational Assessment, 15(2), 123137.

Marchese, S. (2000). Putting square pegs into round holes: Mediation and the rights of children with disabilities under the idea. Rutgers Law Review, 53, 333.

62 
Marden, C. S. (2013). Criteria for transition for self-contained classrooms (Master's thesis, Utah State University, Utah).

Mathes, P. G., Fuchs, D., Roberts, P. H., \& Fuchs, L. S. (1998). Preparing students with special needs for reintegration curriculum-based measurement's impact on transenvironmental programming. Journal of Learning Disabilities, 31(6), 615-624.

McCarthy, M. R., Wiener, R., \& Soodak, L. C. (2012). Vestiges of segregation in the implementation of inclusion policies in public high schools. Educational Policy, 26(2), 309-338.

McLeskey, J., Landers, E., Williamson, P., \& Hoppey, D. (2012). Are we moving toward educating students with disabilities in less restrictive settings? The Journal of Special Education, 46(3), 131-140.

Mukherjee, S., Lightfoot, J., \& Sloper, P. (2000). The inclusion of pupils with a chronic health condition in mainstream school: What does it mean for teachers? Educational Research, 42(1), 59-72.

Nader, A.-M., Courchesne, V., Dawson, M., \& Soulieres, I. (2014). Does wisc-iv underestimate the intelligence of autistic children? Journal of Autism and Developmental Disorders, 1-8.

Nader, A.-M., Courchesne, V., Dawson, M., \& Soulieres, I. (2016). Does wisc-iv underestimate the intelligence of autistic children? Journal of Autism and Developmental Disorders, 46(5), 1582-1589.

Nolan, J. E. (2004). The us individuals with disabilities education act (idea): Tracing inclusion and exclusion of the disabled from ford to bush ii. Online Submission.

Oakland, T., \& Harrison, P. L. (2011). Adaptive behavior assessment system-ii: Clinical use and interpretation. Academic Press.

Popa, A. M., Cruz, J., Angkustsiri, K., Brahmbhatt, K., Cung, N., Leckliter, I., ... Simon, T. J. (2014). Atypical adaptation responses to threat stimuli in children with chromosome 22q11.2 deletion syndrome. In Biological psychology (Vol. 75, 9, 192S-192S).

Praisner, C. L. (2003). Attitudes of elementary school principals toward the inclusion of students with disabilities. Exceptional Children, 69(2), 135-145.

R Development Core Team. (2017). R: A language and environment for statistical computing. ISBN 3-900051-07-0. R Foundation for Statistical Computing. Vienna, Austria. Retrieved from http: / / www.Rproject.org

63 
Raines, T. C., Dever, B. V., Kamphaus, R. W., \& Roach, A. T. (2012). Universal screening for behavioral and emotional risk: A promising method for reducing disproportionate placement in special education. The Journal of Negro Education, 81(3), 283-296.

Reid, R., Gonzalez, J. E., Nordness, P. D., Trout, A., \& Epstein, M. H. (2004). A meta-analysis of the academic status of students with emotional/behavioral disturbance. The Journal of Special Education, 38(3), 130-143.

Reynolds, C. R., \& Shaywitz, S. E. (2009). Response to intervention: Ready or not? or, from wait-to-fail to watch-them-fail. School Psychology Quarterly, 24(2), 130.

Ruth, W. J. (1996). Goal setting and behavior contracting for students with emotional and behavioral difficulties: Analysis of daily, weekly, and total goal attainment. Psychology in the Schools, 33(2), 153-158. doi:10.1002/(SICI) 1520-6807(199604)33:2〈153::AID-PITS8>3.0.CO; 2-S

Savich, C. (2008). Inclusion: The pros and cons-a critical review. Online Submission.

Skiba, R. J., Simmons, A. B., Ritter, S., Gibb, A. C., Rausch, M. K., Cuadrado, J., \& Chung, C.-G. (2008). Achieving equity in special education: History, status, and current challenges. Exceptional Children, 74(3), 264-288.

Smith, R. M. (2006). Classroom management texts: A study in the representation and misrepresentation of students with disabilities. International Journal of Inclusive Education, 10(1), 91-104.

Smith, S. W., \& Farrell, D. T. (1993). Level system use in special education: Classroom intervention with prima facie appeal. Behavioral Disorders, 18(4), 251-264. doi:10.1177/019874299301800408. eprint: http://dx.doi.org/10.1177/019874299301800408

Taub, G. E., \& McGrew, K. S. (2004). A confirmatory factor analysis of cattell-horn-carroll theory and cross-age invariance of the woodcockjohnson tests of cognitive abilities iii. School Psychology Quarterly, 19(1), 72 .

Therneau, T. M., Atkinson, E. J. et al. (2017). An introduction to recursive partitioning using the rpart routines. Technical report Mayo Foundation. 
Wadsworth, D. F. D., \& Knight, D. (1999). Preparing the inclusion classroom for students with special physical and health needs. Intervention in School and Clinic, 34(3), 170-175.

Wechsler, D. (2008). Wechsler adult intelligence scale-fourth. San Antonio: Pearson.

Wiesner, M., \& Schanding, G. T. (2013). Exploratory structural equation modeling, bifactor models, and standard confirmatory factor analysis models: Application to the basc- 2 behavioral and emotional screening system teacher form. Journal of School Psychology, 51(6), 751763.

Wu, W., West, S. G., \& Hughes, J. N. (2008). Short-term effects of grade retention on the growth rate of woodcock-johnson iii broad math and reading scores. Journal of School Psychology, 46(1), 85-105.

Yerkes, R. M., \& Dodson, J. D. (1908). The relation of strength of stimulus to rapidity of habit-formation. Journal of Comparative Neurology and Psychology, 18(5), 459-482.

Zaretskii, V. K. (2009). The zone of proximal development. Journal of Russian \& East European Psychology, 47(6), 70-93. doi:10.2753 / RPO1061-0405470604. eprint: http: / /www.tandfonline.com/doi / pdf/10.2753/RPO1061-0405470604

Zigmond, N., \& Baker, J. M. (1995). Concluding comments: Current and future practices in inclusive schooling. Journal of Special Education, 29, 245-250. 


\section{Appendices}

A Code and Implementation

B Sample SLD Rubric 
Student Name:

DOB:

Grade:

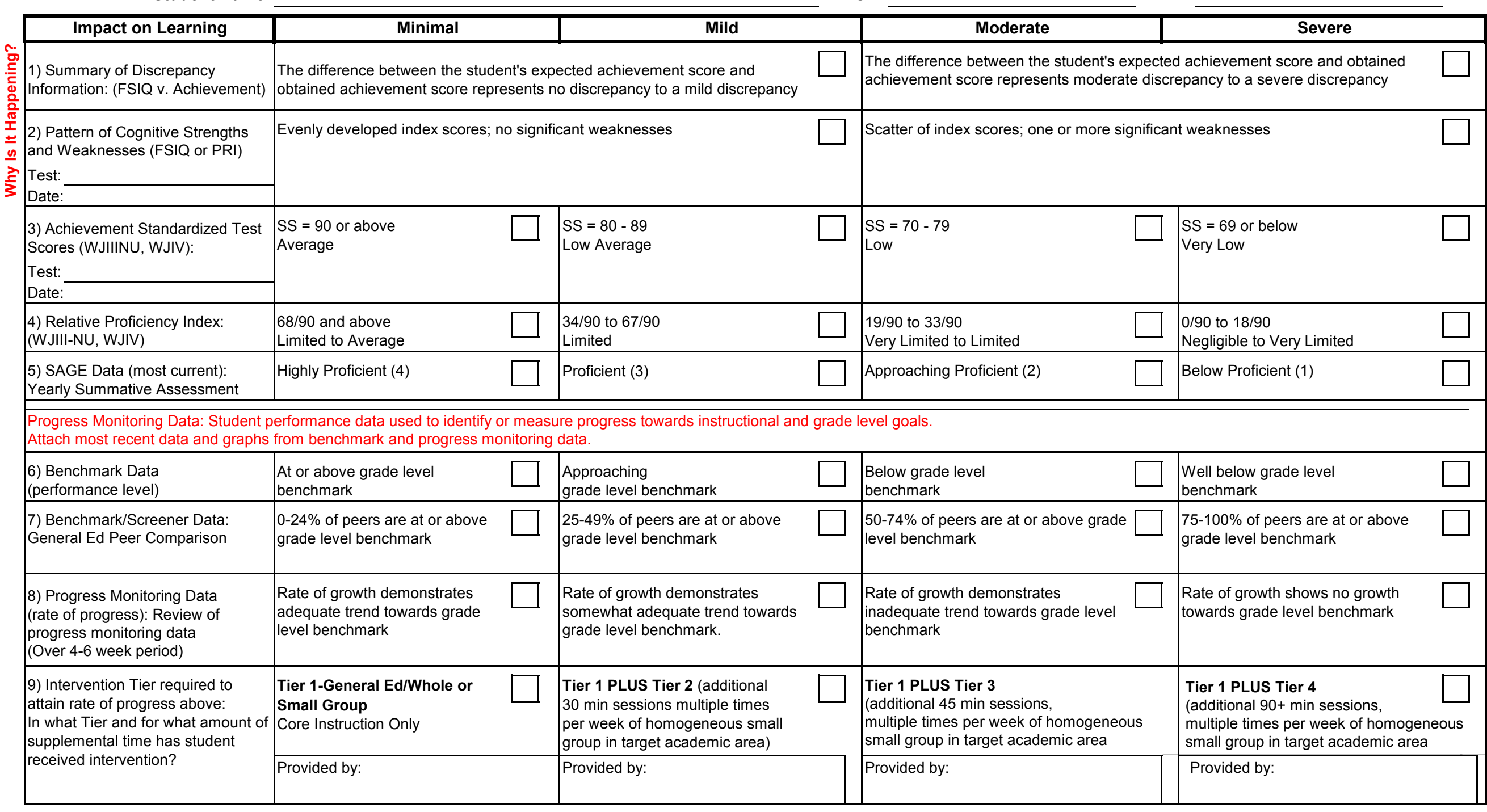

\section{At least 7 of 9 check marks appear in the "Moderate" or "Severe" columns:}

AND at least 5 of the above 7 check marks appear in the "Severe" column:

Eligibility Team has ruled out "considerations" as substantially

impacting the student's educational performance:

Eligibility Team has determined that the student has a Specific Learning Disability in this area:

YES $\square \square$ NO
YES $\square \square_{\text {NES }}^{\text {NeS }} \square$ NO $\square$ NO




\section{Academic Mainstreaming Decision Tree - Academics}




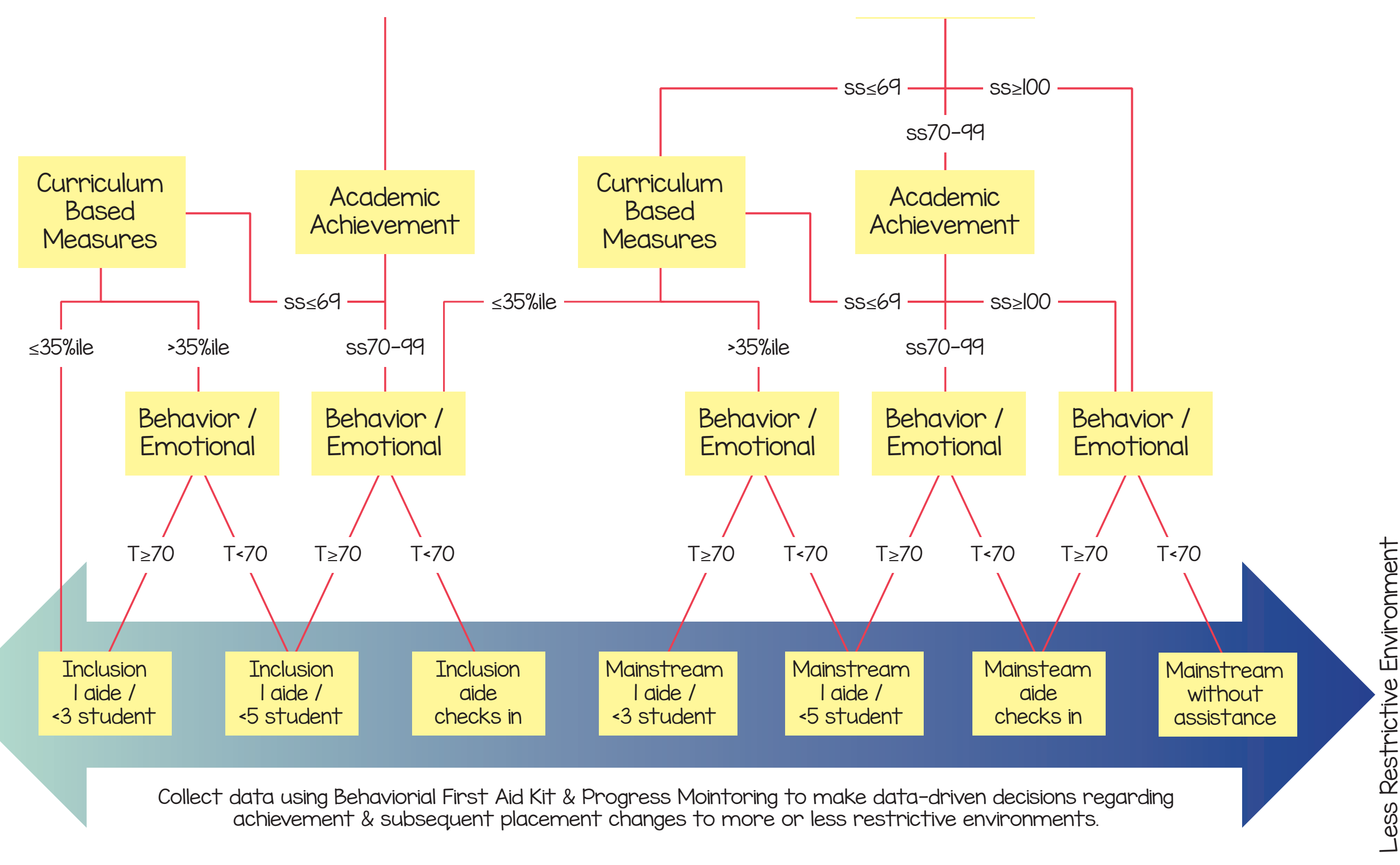




\section{Academic Mainstreaming Decision Tree - Be- havior}




\section{Behavior Mainstreaming Progress Decision Tree}

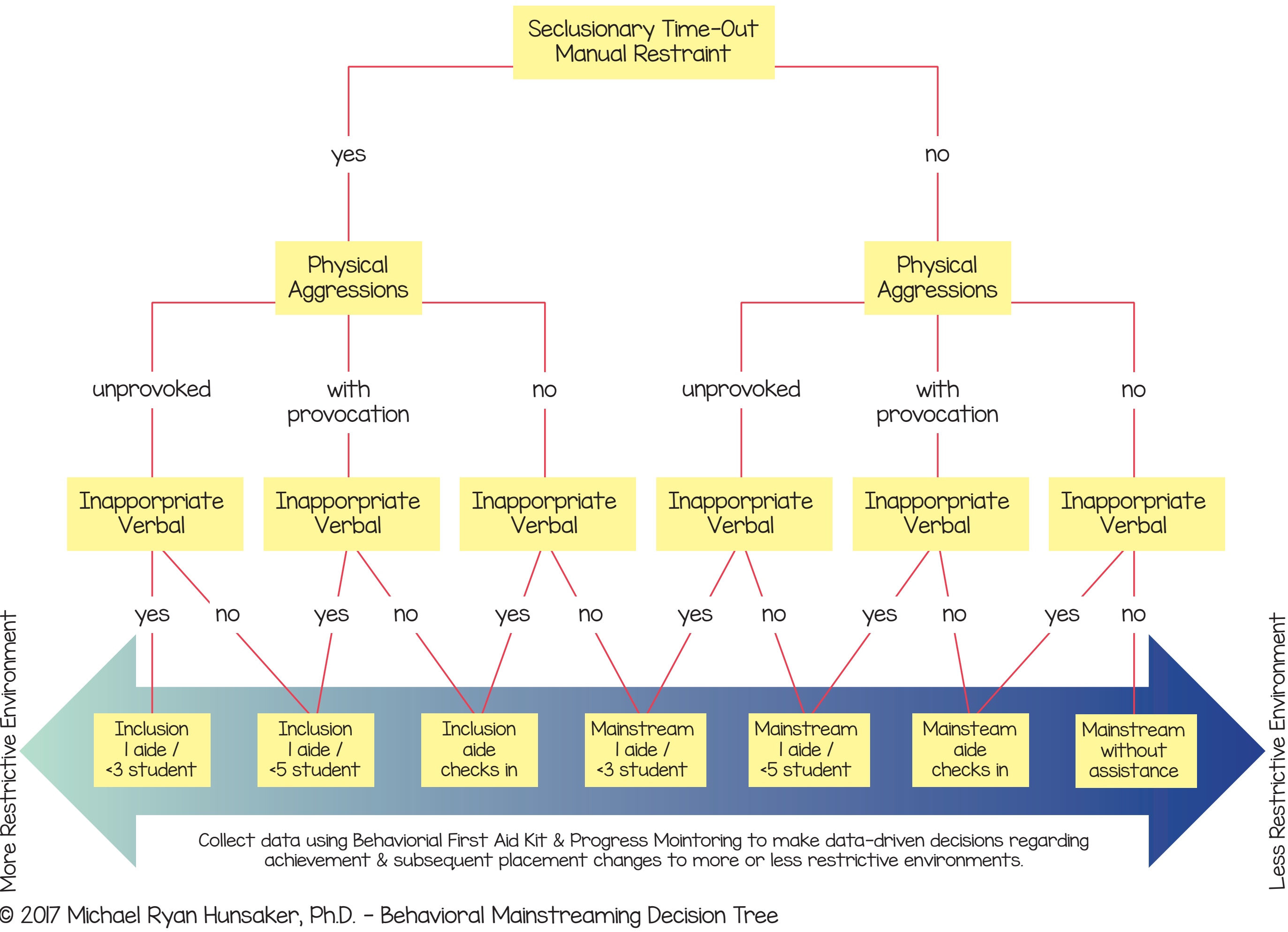




\section{E Mainstreaming Plan Form}




\section{Special Education Mainstreaming Plan}

Name:

School:
Grade: Classification
Teacher:

Date of Review:

\begin{tabular}{|r|r|r|r|}
\hline \multicolumn{2}{|c|}{ Formal Assessments } & \multicolumn{1}{|c|}{ Informal Assessments } \\
\hline Cognitive & & Reading & \\
\hline Achievement & & Writing & \\
\hline Adaptive & & Math & \\
\hline Communication & & Behavior & \\
\hline Behavior & & $\begin{array}{r}\text { Related } \\
\text { Services }\end{array}$ & \\
\hline Other & & Other & \\
\hline
\end{tabular}

\begin{tabular}{|c|c|c|c|c|}
\hline Mainstreaming Expectations & Developing & Expanding & Independent & Needed Instruction/Support \\
\hline \multicolumn{4}{|l|}{ Follows Classroom Routines and Rules } & \\
\hline 1. Complies with directions & & & & \\
\hline 2. Follows classroom routines & & & & \\
\hline $\begin{array}{l}\text { 3. Handles transitions and accepts change to } \\
\text { rules, routines and/or procedures }\end{array}$ & & & & \\
\hline \multicolumn{4}{|l|}{ Academic Learning } & \\
\hline 1. Actively participates in learning tasks & & & & \\
\hline $\begin{array}{l}\text { 2. Volunteers answers (raise hand and wait to be } \\
\text { called on) }\end{array}$ & & & & \\
\hline 3. Completes assignments & & & & \\
\hline 4. Reads orally & & & & \\
\hline 5. Asks for help & & & & \\
\hline 6. Participates in partner or group work & & & & \\
\hline \multicolumn{4}{|l|}{ Social Emotional Learning } & \\
\hline 1. Communicates and interacts with peers & & & & \\
\hline 2. $\quad$ Ability to respond to frustration(s) & & & & \\
\hline 3. Ability to problem solve & & & & \\
\hline 4. Stays in seat or assigned area & & & & \\
\hline \multicolumn{4}{|l|}{$\overline{\text { Organizational Skills }}$} & \\
\hline \multicolumn{4}{|l|}{$\begin{array}{l}\text { 1. Able to utilize a planner or calendar to track } \\
\text { assignment }\end{array}$} & \\
\hline $\begin{array}{l}\text { Utilizes and manages necessary materials } \\
\text { (notebook, binder, pencil pouch, etc.) }\end{array}$ & & & & \\
\hline $\begin{array}{l}\text { 3. Completes and turns in assignments (in class } \\
\text { and/or homework) }\end{array}$ & & & & \\
\hline 4. Written work legible and neat & & & & \\
\hline
\end{tabular}

Note: Provide the minimum supports necessary for success then gradually fade to increase independence Accepted for Pubfication in "The European Journal of Education Studies" 
Mainstreaming Plan

\section{Special Education Mainstreaming Plan}

\begin{tabular}{|l|l|l|l|}
\hline Start Date & Subject & Teacher/Classroom & Time \\
\hline & & & \\
\hline & & & \\
\hline & & & \\
\hline
\end{tabular}

\section{Notes}

\section{Monitoring}

Who will be responsible for monitoring progress:

How frequently will monitoring take place? Daily

How implementation and outcomes be evaluated?

Weekly

Bimonthly

Monthly

Teacher Monitoring:

Student Monitoring:

\section{Signature of Team Members:}

Mainstream Review - Mainstreaming data review and changes to mainstreaming schedule.

Date: 


\section{F Classroom Ecological Inventory (K-6)}

Accepted for Publication in "The European Journal of Education Studies" 


\section{Classroom Ecological Inventory}

General Education Teacher

Special Education Teacher

Principal

School

Answer the following questions to best describe your classroom and teaching practices

Grade/s Taught (mark all that apply)

$\square$ ist grade

$\square$ 2nd grade

$\square$ 3rd grade

I am a teacher

$\square$ Core

$\square$ Elective

$\square$ Resource $\square$ 4th grade

$\square$ 5th grade

$\square$ 6th grade

At minimum I expect students to be at a grade reading level

$\square$ Pre-Kindergarten

$\square$ 3rd-4th

$\square$ Kindergarten

$\square$ 5th-6th

$\square$ Ist-2nd

$\square$ No expectation

At minimum I expect students to be at a grade writing level

$\square$ Pre-Kindergarten

$\square$ Kindergarten

$\square$ Ist-2nd $\square$ 3rd-4th

$\square$ 5th-6th

$\square$ No expectation 
Answer the following questions to best describe your classroom and teaching practices At minimum I expect students to be at a grade math level

$\square$ Pre-Kindergarten

$\square 3 r d-4 t h$

$\square$ Kindergarten

$\square$ 5th-6th

$\square$ Ist-2nd

$\square$ No expectation

At minimum I expect students to bring assigned materials $\%$ of the time

$\square 0-9 \%$

$\square 9-24 \%$

$\square 25-49 \%$ $\square 50-74 \%$

$\square 75-100 \%$

$\square$ No expectation

At minimum I expect students to stay in their seat $\%$ of the time

$\square 0-9 \%$

$\square 9-24 \%$

$\square 25-49 \%$ $\square 50-74 \%$

$\square 75-100 \%$

$\square$ No expectation

At minimum I expect students to stay quiet $\%$ of the time

$\square 0-9 \%$

$\square-24 \%$

$-25-49 \%$ $\square 50-74 \%$

$\square 75-100 \%$

$\square$ No expectation

At minimum I expect students to work w/o teacher attention $\%$ of the time
$\square 0-9 \%$
$\square 50-74 \%$
$\square$ 9-24\%
$\square 75-100 \%$
$\square 25-49 \%$
$\square$ No expectation 
Answer the following questions to best describe your classroom and teaching practices

Most worksheets in my class are:

$\square$ Fill In the Blank

$\square$ Multiple Choice

$\square$ Short Answer $\square$ Long Answer

$\square$ Essay

$\square$ Show Work

Most quizzes in my class are:

$\square$ Fill In the Blank

$\square$ Multiple Choice

$\square$ Short Answer $\square$ Long Answer

$\square$ Essay

$\square$ Show Work

Most tests in my class are:

$\square$ Fill In the Blank

$\square$ Long Answer

$\square$ Multiple Choice

$\square$ Essay

$\square$ Short Answer

$\square$ Show Work

Homework, worksheets, and assignments are accepted:

$\square$ Not accepted late

$\square$ Within the term

$\square$ Within I week

$\square$ Until end of year

$\square$ Within 2 weeks

$\square$ No expectation

Quizzes and Tests are accepted:

$\square$ Not accepted late

$\square$ Within I week

$\square$ Within 2 weeks $\square$ Within the term

$\square$ Until end of year

$\square$ No expectation 
Answer the following questions to best describe your classroom and teaching practices

I collect Homework by:

$\square$ Calling for it during class

$\square$ No prompts

$\square$ Collect from students

$\square$ Back and forth folder

$\square$ Remind student to turn in

$\square$ No expectation

I collect quizzes by:

$\square$ Calling for it during class $\quad \square$ No prompts

$\square$ Collect from students

$\square$ Back and forth folder

Remind student to turn in

$\square$ No expectation

I collect tests by:

$\square$ Calling for it during class

$\square$ No prompts

Collect from students

$\square$ Back and forth folder

Remind student to turn in

$\square$ No expectation

I collect in class worksheets by:

$\square$ Calling for it during class

$\square$ No prompts

$\square$ Collect from students

$\square$ Back and forth folder

$\square$ Remind student to turn in

$\square$ No expectation

Students are requires to take notes from lecture by:

$\square$ Free hand

$\square$ Copy from board

$\square$ Fill in blanks $\square$ Graphic Organizer

$\square$ Notes provided

$\square$ No expectation 
Answer the following questions to best describe your classroom and teaching practices

Students are required to take notes from movies by:

$\square$ Free hand

$\square$ Graphic Organizer

$\square$ Copy from board

$\square$ Notes provided

$\square$ Fill in blanks

$\square$ No expectation

Chromebooks or iPads are used in my classroom $\%$ of the time
$\square 0-9 \%$
$\square 50-74 \%$
$\square 9-24 \%$
$\square 75-100 \%$
$25-49 \%$
$\square$ No expectation

If you feel an important skill or expectation concerning transition was not addressed, please comment here:

For office use only:

Date of completion

Data input

Reconciliation meeting date

Next Steps

Accepted for Publication in "The European Journal of Education Studies" 